Nuclear Technology

Nuclear Technology

Nuclear Technology

Nuclear Technology

Nuclear Technology

Nuclear Technology

Nuclear Technology

Nuclear Technology

Nuclear Technology

Nuclear Technology

Nuclear Technology

Nuclear Technology

Nuclear Technology

Nuclear Technology

Nuclear Technology

Nuclear Technology

Nuclear Technology

Nuclear Technology

Nuclear Technology

A Finite Difference Model Used to Predict the Consolidation of a Ceramic Waste Form Produced from the Electrometallurgical Treatment of Spent Nuclear Fuel

Nuclear Technology Nuclear Technology Nuclear Technology Nuclear Technology Nuclear Technology Nuclear Technology Nuclear Technology Nuclear Technology Nuclear Technology Nuclear Technology Nuclear Technology Nuclear Technology Nuclear Technology Nuclear Technology Nuclear Technology Nuclear Technology Nuclear Technology Nuclear Technology Nuclear Technology Nuclear Technology

by K. J. Bateman and D. D. Capson

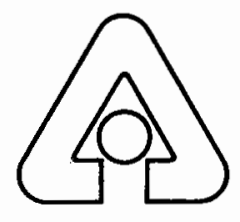

Argonne National Laboratory, Argonne, Illinois 60439 operated by The University of Chicago

for the United States Department of Energy under Contract W-31-109-Eng-38 
Argonne National Laboratory, a U.S. Department of Energy Office of Science laboratory, is operated by The University of Chicago under contract W-31-109-Eng-38.

DISCLAIMER
This report was prepared as an account of work sponsored by an agency of
the United States Government. Neither the United States Government nor
any agency thereof, nor The University of Chicago, nor any of their
employees or officers, makes any warranty, express or implied, or assumes
any legal liability or responsibility for the accuracy, completeness, or
usefulness of any information, apparatus, product, or process disclosed, or
represents that its use would not infringe privately owned rights. Reference
herein to any specific commercial product, process, or service by trade name,
trademark, manufacturer, or otherwise, does not necessarily constitute or
imply its endorsement, recommendation, or favoring by the United States
Government or any agency thereof. The views and opinions of document
authors expressed herein do not necessarily state or reflect those of the
United States Government or any agency thereof.

Available electronically at http://www.osti.gov/bridge/

Available for a processing fee to U.S. Department of Energy and its contractors, in paper, from:

U.S. Department of Energy

Office of Scientific and Technical Information

P.O. Box 62

Oak Ridge, TN 37831-0062

phone: (865) 576-8401

fax: (865) 576-5728

email: reports@adonis.osti.gov 


\section{A FINITE DIFFERENCE MODEL USED TO PREDICT THE CONSOLIDATION OF A CERAMIC WASTE FORM PRODUCED FROM THE ELECTROMETALLURGICAL TREATMENT OF SPENT NUCLEAR FUEL}

K. J. Bateman and D. D. Capson

Engineering Technology Division

Argonne National Laboratory-West

P. O. Box 2528

Idaho Falls, ID 83403-2528

NT TECHNICAL MEMORANDUM NO. 209

Results reported in the NT-TM series of memoranda frequently are preliminary and subject to revisions. Consequently they should not be quoted or referenced. 


\section{TABLE OF CONTENTS}

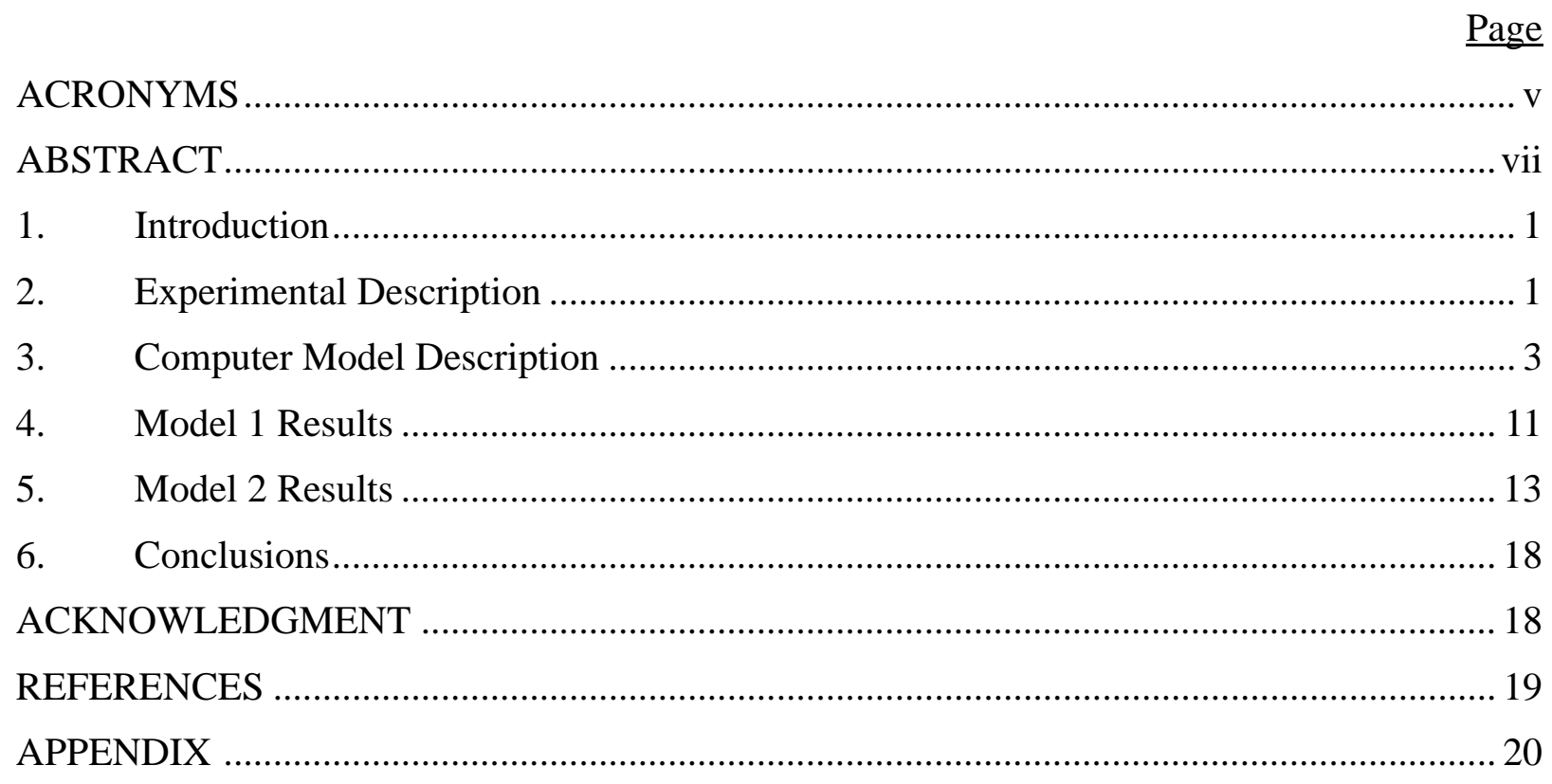




\section{LIST OF FIGURES}

Page

1. Geometry of $25 \mathrm{~kg}$ Experimental Canister and Top Plate ............................................... 2

2. Geometry of CWF and Mesh of Plane A................................................................. 7

3. Bulk Density Versus Soak Time for Ceramic Waste Form............................................... 8

4. Experiment Setup of Linear Potentiometer ................................................................ 9

5. Height of Production Canister Versus Ceramic Waste Form Mass .................................... 11

6. Ceramic Waste Form Temperature Versus Mass ............................................................. 12

7. Production Size Ceramic Waste Form Core Temperature Versus Time ............................. 12

8. Temperature Versus Time for $25 \mathrm{~kg}$ Ceramic Waste Form Model ..................................... 13

9. Bulk Density Versus Time for the $25 \mathrm{~kg}$ Ceramic Waste Form Model ............................... 14

10. Experimental Data from 25 kg Ceramic Waste Form Experiment ................................... 14

11. Comparison of Model 2 Versus $25 \mathrm{~kg}$ Experimental Temperature Data ............................. 15

12. Comparison Model 2 Versus 25 kg Experimental Bulk Density Data ................................ 16

13. Comparison of Model 2 Versus $140 \mathrm{~kg}$ Experimental Temperature Data ........................... 17

14. Comparison of Model 2 Versus 140 kg Experimental Bulk Density Data.......................... 18 


\section{ACRONYMS}

$\begin{array}{ll}\text { ANL } & \text { Argonne National Laboratory } \\ \text { ANL-East } & \text { Argonne National Laboratory-East } \\ \text { ANL-West } & \text { Argonne National Laboratory-West } \\ \text { EBR-II } & \text { Experimental Breeder Reactor-II } \\ \text { CMT } & \text { Chemical Technology Division } \\ \text { CWF } & \text { Ceramic Waste Form } \\ \text { EDL } & \text { Engineering Development Laboratory } \\ \text { HFEF } & \text { Hot Fuel Examination Facility } \\ \text { PC } & \text { Pressureless Consolidation }\end{array}$




\section{LIST OF SYMBOLS}

\begin{tabular}{ll}
$\mathrm{Bi}$ & Biot Number \\
$\mathrm{C}$ & Concentration \\
$\mathrm{C}_{\mathrm{O}}$ & Initial Concentration \\
$\mathrm{Cp}$ & Heat Capacity \\
$\mathrm{C}_{\mathrm{r}}$ & Constant for Infinite Cylinder Exact Solution Equation \\
$\mathrm{E}$ & Activation Energy/Universal Gas Constant \\
$\mathrm{F}_{\mathrm{o}}$ & Fourier Number \\
$\mathrm{i}$ & Nodal Coordinate in Axial Direction \\
$\mathrm{j}$ & Nodal Coordinate in Radial Direction \\
$\mathrm{J} 0$ & Bessel Function of Order 0 \\
$\mathrm{~J} 1$ & Bessel Function of Order 1 \\
$\mathrm{k}$ & Thermal Conductivity \\
$\mathrm{L}$ & Length \\
$\mathrm{p}$ & Time Step Number \\
$\mathrm{R}$ & Radius \\
$\mathrm{r}$ & Dimensionless Radius \\
$\mathrm{T}$ & Temperature \\
$\mathrm{x}$ & Time \\
\hline
\end{tabular}

\section{Greek}

$\begin{array}{ll}\alpha & \text { Thermal Diffusivity } \\ \beta & \text { Order of Temperature } \\ \Delta \mathrm{r} & \text { Distance Between Radial Nodes } \\ \Delta \mathrm{z} & \text { Thermal Diffusivity } \\ \theta & \text { Dimensionless Temperature } \\ \rho & \text { Density } \\ \zeta_{\mathrm{r}} & \text { Positive Roots of a Transcendental Equation for an Infinite Cylinder } \\ \zeta_{\mathrm{X}} & \text { Positive Roots of a Transcendental Equation for a Plane Wall }\end{array}$




\title{
A FINITE DIFFERENCE MODEL USED TO PREDICT THE CONSOLIDATION OF A CERAMIC WASTE FORM PRODUCED FROM THE ELECTROMETALLURGICAL TREATMENT OF SPENT NUCLEAR FUEL
}

by

K. J. Bateman and D. D. Capson

\begin{abstract}
Argonne National Laboratory (ANL) has developed a process to immobilize waste salt containing fission products, uranium, and transuranic elements as chlorides in a glass-bonded ceramic waste form. This salt was generated in the electrorefining operation used in the electrometallurgical treatment of spent Experimental Breeder Reactor-II (EBR-II) fuel. The ceramic waste process culminates with an elevated temperature operation. The processing conditions used by the furnace, for demonstration scale and production scale operations, are to be developed at Argonne National Laboratory-West (ANL-West). To assist in selecting the processing conditions of the furnace and to reduce the number of costly experiments, a finite difference model was developed to predict the consolidation of the ceramic waste. The model accurately predicted the heating as well as the bulk density of the ceramic waste form. The methodology used to develop the computer model and a comparison of the analysis to experimental data is presented.
\end{abstract}




\section{Introduction}

Argonne National Laboratory (ANL) developed a process to immobilize the waste salt stream from the electrometallurgical treatment of spent Experimental Breeder Reactor-II (EBR-II) fuel in a glass-bonded ceramic waste form [1]. The waste salt stream consisted of spent electrolyte (LiCl-KCl eutectic) containing alkali, alkali earth, lanthanide, and actinide fission products present as chloride salts. In making the ceramic waste form, these halides were first occluded into the pores of zeolite-4A using an elevated temperature blending process. Salt loaded zeolite was then mixed with glass frit and loaded into cylindrical stainless steel canisters. Finally, they were subjected to elevated temperature in a furnace. The resulting ceramic waste form (CWF) was a glass-bonded sodalite suitable for long-term storage in a repository.

The Chemical Technology Division (CMT) at Argonne National Laboratory-East (ANL-East) performed initial development tests for this process. Lab-scale experiments were performed using relatively small sample sizes of $20 \mathrm{~g}$. These experiments have shown that a process time of 8 to 24 hours at greater than $900^{\circ} \mathrm{C}$ results in a densification of 2:1. It has been recommended that a temperature of $915^{\circ} \mathrm{C}$ be used to optimize the procedure [2]. At Argonne National LaboratoryWest (ANL-West), the process was scaled-up to produce demonstration-scale CWF (up to $150 \mathrm{~kg}$ ), and will eventually be used for CWF production-scale (greater than $150 \mathrm{~kg}$ ). The demonstration-scale effort included processing of nonirradiated material in the Engineering Development Laboratory (EDL) and continued with processing of irradiated material in the Hot Fuel Examination Facility (HFEF). Eventually, the production-scale effort will follow a similar path. To assist in selecting the operating conditions of the furnace and to reduce the number of costly experiments, a finite difference model was developed to predict the consolidation of the ceramic waste. The details of this model and a comparison with experimental data will be the primary focus of this report.

\section{Experimental Description}

Each experiment consisted primarily of CWF material contained in a stainless steel can, that was processed (soaked) in a furnace at $915^{\circ} \mathrm{C}$. A stainless steel plug rested on top of the waste material to level the surface of the material. The plug applied a load of approximately 1-psi. Thermocouples were placed in strategic locations within the waste material in order to measure temperature. To measure the vertical displacement, a linear potentiometer was placed on top of the plug. Since the geometry of each experiment was cylindrical, and radius remains constant, vertical displacement measured by the potentiometer was directly related to the material's volume and density.

$$
V=H \cdot \pi \cdot R^{2}
$$

where:

$V=$ volume $\left(\mathrm{m}^{3}\right)$

$H=$ height $(\mathrm{m})$

$R=\operatorname{radius}(\mathrm{m})$

and 


$$
\rho=M / V
$$

where:

$\rho=$ density of material $\left(\mathrm{kg} / \mathrm{m}^{3}\right)$

$M=$ mass of material $(\mathrm{kg})$

After various small-scale experiments were conducted to obtain initial thermophysical data, a $25 \mathrm{~kg}$ experiment was conducted to test the computer model, specifically thermal conductivity $(\mathrm{k})$, density $(\rho)$, and heat capacity (Cp). A stainless steel can with an inner radius of $12.4 \mathrm{~cm}$ and a height of $61 \mathrm{~cm}$ was filled with $25 \mathrm{~kg}$ of salt-loaded zeolite/glass mixture. The can was tapped for $5 \mathrm{~min}$ resulting in a green geometric density of $0.91 \mathrm{~g} / \mathrm{cm}^{3}$. Three $1.6 \mathrm{~mm}$ thermocouples were inserted through thermal wells located in the bottom of the can to heights of $15.25 \mathrm{~cm}$, $22.8 \mathrm{~cm}$, and $15.25 \mathrm{~cm}$, respectively. The first two were located in the center of the can radially, whereas the third was located $8.9 \mathrm{~cm}$ from the radial center (Fig. 1a). A fourth thermocouple was spot welded onto the outside surface of the can and was used as the furnace control thermocouple. A $3.175 \mathrm{~mm}$ thick stainless steel plate was placed on top of the material. To keep the top surface level, four additional weights, totaling $24.75 \mathrm{~kg}$, were placed on top of the top plate (Fig. 1b). The can and material were placed in a furnace with internal working dimensions of $61 \mathrm{~cm} \times 61 \mathrm{~cm} \times 76 \mathrm{~cm}$. A linear potentiometer with a measuring range of $60 \mathrm{~cm}$ was mounted above the furnace with an attached $6.35 \mathrm{~mm}$ stainless steel rod protruding through a hole centered in the ceiling of the furnace and resting on the top plate of the can (Fig. 1b). The furnace was ramped from room temperature to $500^{\circ} \mathrm{C}$ at $5^{\circ} \mathrm{C} / \mathrm{min}$. The furnace was held at $500^{\circ} \mathrm{C}$ for 30 hours and then ramped to $915^{\circ} \mathrm{C}$ at $1{ }^{\circ} \mathrm{C} / \mathrm{min}$. The furnace held at $915^{\circ} \mathrm{C}$ for $48 \mathrm{~h}$ and then was shut off.

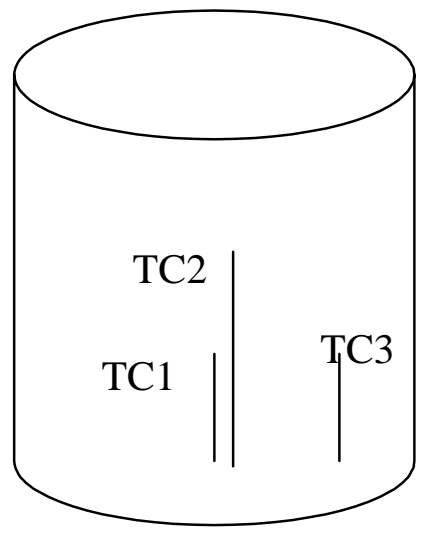

(a)

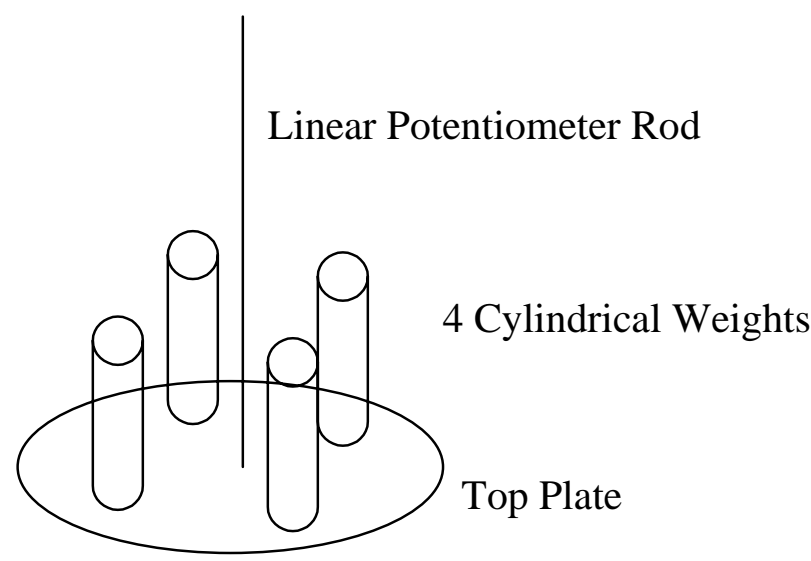

(b)

Fig. 1. (a) Geometry of 25 kg Experimental Canister and (b) Top Plate 


\section{Computer Model Description}

Two separate computer models were developed to predict densification rates for given CWF mass and soak times. The first model used exact solution equations and constant properties in order to bound soak times between best and worst case scenarios. The second model used transient, finite difference equations to incorporate changing thermophysical properties during processing. Both models were created using the software package MathCad 2001 [3].

The first model was based on the following equations. First, assuming a planar wall is [4]:

$$
\theta_{x}=\sum_{n=1}^{\infty} C_{X_{n}} \cdot \exp \left[-\left(\zeta_{x_{n}}\right)^{2} \cdot F o\right] \cdot \cos \left(\zeta_{X_{n}} \cdot x\right)
$$

where:

$\theta=$ dimensionless temperature

$\mathrm{x}=$ dimensionless height

$\zeta=$ positive root

$F_{O}=$ Fourier Number $=\alpha \mathrm{t} / \mathrm{L}^{2}$

$\mathrm{t}=$ time $(\mathrm{s})$

$\mathrm{L}$ = length (m)

$\alpha=$ thermal diffusivity, defined as $\mathrm{k} / \mathrm{\rho} \cdot \mathrm{C}_{\mathrm{p}}\left(\mathrm{m}^{2} / \mathrm{s}\right)$

$k$ = thermal conductivity $(\mathrm{W} / \mathrm{m} \cdot \mathrm{K})$

$C_{p}=$ heat capacity $(\mathrm{J} / \mathrm{kg} \cdot \mathrm{K})$

$\mathrm{Cx}_{\mathrm{n}}$, a constant for the plane wall exact solution, is:

$$
C_{X_{n}}=\frac{4 \sin \left(\zeta_{X_{n}}\right)}{2 \zeta_{X_{n}}+\sin \left(2 \cdot \zeta_{X_{n}}\right)}
$$

And the discrete values (eigenvalues) of $\zeta x_{n}$ are positive roots of the transcendental equation:

$$
\zeta_{X_{n}} \cdot \tan \left(\zeta_{X_{n}}\right)=B i
$$


Secondly, assuming an infinite cylinder, [4]

$$
\theta_{r}=\sum_{n=1}^{\infty} C_{r_{n}} \cdot \exp \left[-\left(\zeta_{r_{n}}\right)^{2} \cdot F o\right] \cdot J 0\left(\zeta_{r_{n}} \cdot r\right)
$$

where $F o=\alpha \cdot \mathrm{t} / \mathrm{R}^{2}$ and $\mathrm{Cr}_{\mathrm{n}}$ is:

$$
C_{r_{n}}=\frac{2}{\zeta_{r_{n}}} \cdot \frac{J 1\left(\zeta_{r_{n}}\right)}{J 0\left(\zeta_{r_{n}}\right)^{2}+J 1\left(\zeta_{r_{n}}\right)^{2}}
$$

and the discrete values of $\zeta r_{n}$ are positive roots of the transcendental equation:

$$
\zeta_{r_{n}} \cdot \frac{J 1\left(\zeta_{r_{n}}\right)}{J 0\left(\zeta_{r_{n}}\right)}=B i
$$

where the quantities $J 1$ and $J 0$ are Bessel functions of the first kind and $\theta$ is a dimensionless temperature parameter which is equal to the product of $\theta_{\mathrm{x}}$ and $\theta_{\mathrm{r}}$ [4].

$$
\theta=\theta_{x} \times \theta_{r}=\left(T-T_{\infty}\right) /\left(T_{i}-T_{\infty}\right)
$$

where:

$T=$ temperature $(\mathrm{K})$

The $\mathrm{x}$ and $\mathrm{r}$ represent dimensionless positions as $\mathrm{x}=$ height/total height and $\mathrm{r}=$ radius/total radius. The model was based on the assumption that the Biot number $(\mathrm{Bi})$ was infinite or, in other words, the surface temperature was equal to the furnace temperature.

The equations used in model 1 represent exact solutions for constant property analysis [4]. However, to successfully model a transient process with varying properties, a different approach was needed. Model 2 (Appendix A) utilized a finite difference approximation in order to incorporate varying properties, i.e., thermal conductivity, density, and heat capacity, into the model. This model was created to predict processing conditions necessary to achieve the desired consolidation of the CWF and utilized fundamental heat transfer equations [5]. The first equation (10), Fourier's law states that:

$$
q / A=-k \cdot \nabla T
$$

where: 
$q=$ heat flux $(\mathrm{W})$

$A=$ area $\left(\mathrm{m}^{2}\right)$

$T=$ temperature $(\mathrm{K})$

$\nabla=$ Del operator (for cylindrical coordinates $\nabla=\mathrm{i} \mathrm{d} / \mathrm{dr}+\mathrm{j} 1 / \mathrm{r} \mathrm{d} / \mathrm{d} \theta+\mathrm{k} \mathrm{d} / \mathrm{dz}$ )

The second equation utilized is the conservation of energy (Eq. 11) shown below.

$$
E_{\text {in }}+E_{g}-E_{\text {out }}=E_{\text {st }}
$$

where:

$E_{\text {in }} \quad=$ entering energy (W)

$E_{g} \quad$ = generated energy (W)

$E_{\text {out }}=$ exiting energy $(\mathrm{W})$

$E_{\text {st }} \quad=$ stored energy $(\mathrm{W})$

The entering and exiting energy terms are represented by Fourier's law Eq. (10). The generation and storage terms are represented by Eqs. (12) and (13), respectively.

$$
\begin{gathered}
E_{g}=q_{g} d V \\
E_{s t}=\rho \cdot C_{p} d T / d t d V
\end{gathered}
$$

where:

$q_{g}=$ generated heat $\left(\mathrm{W} / \mathrm{m}^{3}\right)$

The generation heat term $\left(q_{g}\right)$ can be further reduced into separate heat generating terms as shown by Eq. (14).

$$
q_{g}=q_{r a d}+q_{H r}+q_{P V}
$$

where:

$q_{\text {rad }}=$ generation due to radioactivity $\left(\mathrm{W} / \mathrm{m}^{3}\right)$

$q_{\mathrm{Hr}}=$ generation due to heat of reaction $\left(\mathrm{W} / \mathrm{m}^{3}\right)$

$q_{P V}=$ generation due to pressure-volume work $\left(\mathrm{W} / \mathrm{m}^{3}\right)$ 
Combining Eqs. (10) through (14), the general form of the heat equation in cylindrical coordinates is

$$
\frac{1}{r} \cdot \frac{\partial}{\partial r}\left(k \cdot r \cdot \frac{\partial}{\partial r} T\right)+\frac{1}{r^{2}} \cdot \frac{\partial}{\partial \theta}\left(k \cdot \frac{\partial}{\partial \theta} T\right)+\frac{\partial}{\partial z}\left(k \cdot \frac{\partial}{\partial z} T\right)+q_{r a d}+q_{H r}+q_{P V}=\rho \cdot C_{p} \cdot \frac{\partial}{\partial t} T
$$

Making the assumptions that thermal conductivity $(\mathrm{k})$ varies with time and not with position, and that there are no gradients in the $\theta$ direction, Eq. (15) can be simplified to Eq. (16).

$$
\frac{1}{\alpha} \cdot \frac{\partial}{\partial t} T=\frac{1}{r} \frac{\partial}{\partial r}\left(r \cdot \frac{\partial}{\partial r} T\right)+\frac{\partial^{2}}{\partial z^{2}} T+\frac{q_{r a d}}{k}+\frac{q_{H r}}{k}+\frac{q_{P V}}{k}
$$

Defining the parameter $p$ as the time step number

$$
p=t / \Delta t
$$

then utilizing the definition of $p, d T / d t$ becomes

$$
\frac{d}{d t} T=\frac{T(p+1)_{i, j}-T(p)_{i, j}}{\Delta t}
$$

then Eq. (16) becomes Eq. (19).

$$
\left(T_{p+1}\right)_{i, j}=\alpha \cdot \Delta t \cdot\left[\begin{array}{c}
\frac{\left(T_{p}\right)_{i+1, j}+\left(T_{p}\right)_{(i-1), j}-2 \cdot\left(T_{p}\right)_{i, j}}{\Delta z^{2}} \ldots \\
+\frac{\left(T_{p}\right)_{i, j+1}+\left(T_{p}\right)_{i, j-1}-2 \cdot\left(T_{p}\right)_{i, j}}{\Delta r^{2}} \ldots \\
+\frac{1}{r} \cdot \frac{\left(T_{p}\right)_{i, j-1}-\left(T_{p}\right)_{i, j+1}}{2 \cdot \Delta r}+\frac{q_{g}}{k}
\end{array}\right]+\left(T_{p}\right)_{i, j}
$$

where:

$p=$ time step number ranging from 0 to the defined number of time steps

$i=$ node number in the $\mathrm{z}$ direction

$j=$ node number in the $\mathrm{r}$ direction

$\Delta t=$ length of time step $\mathrm{p}(\mathrm{s})$ 
$\Delta z=$ distance between nodes in $\mathrm{z}$ direction $(\mathrm{m})$

$\Delta r=$ distance between nodes in the $\mathrm{r}$ direction (m)

The parameters $\Delta \mathrm{z}$ and $\Delta \mathrm{r}$ are the distances between axial and radial nodes, respectively, as shown in Fig. 2. They are calculated by the user-input number of nodes in each direction. The greater the number of nodes, the smaller $\Delta \mathrm{z}$ and $\Delta \mathrm{r}$ become. Larger values of nodes served to increase accuracy, but also greatly increased computation time.

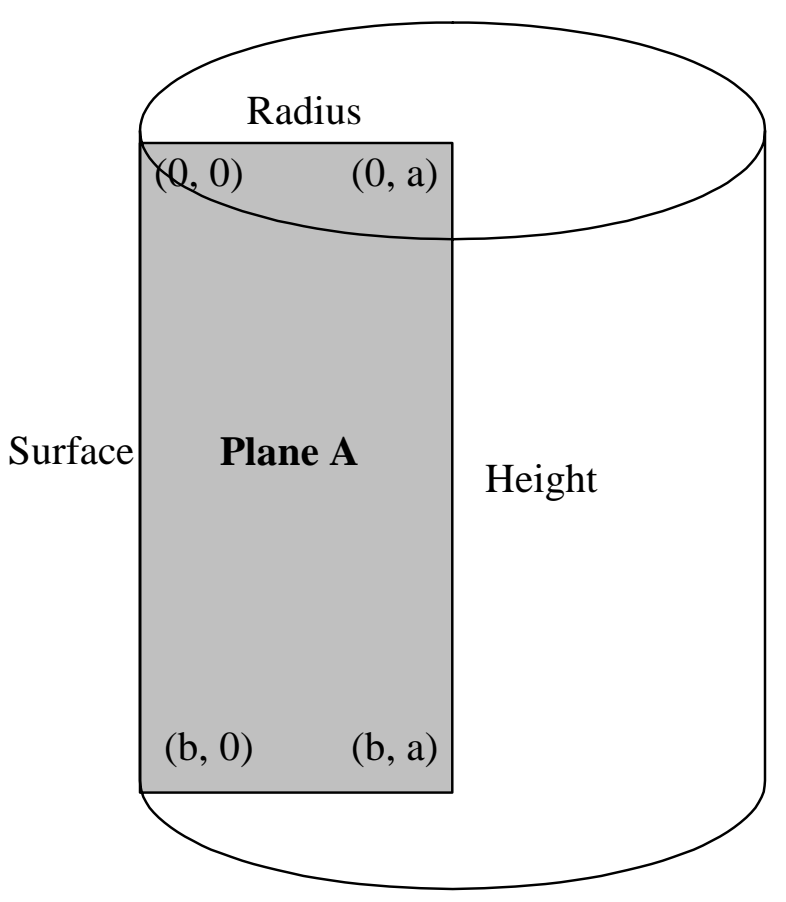

(a)

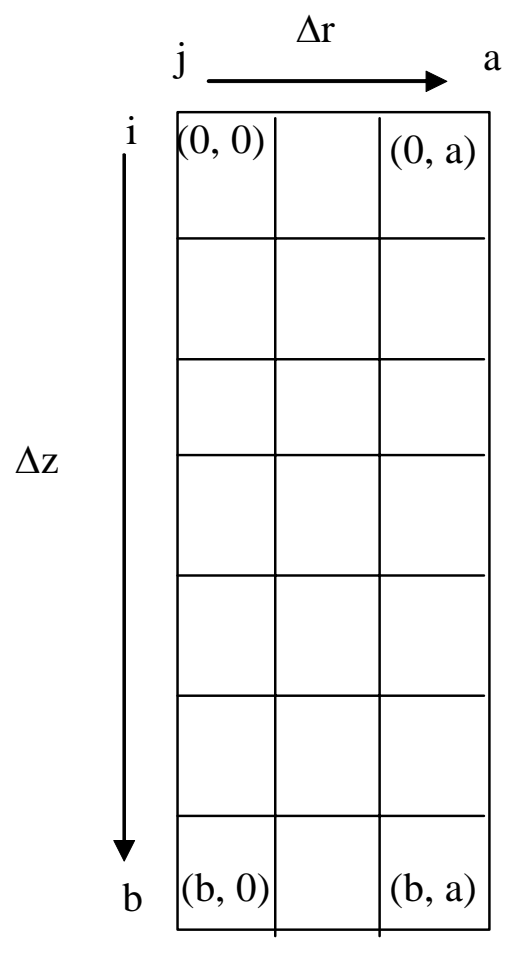

(b)

Fig. 2. (a) Geometry of CWF and (b) Mesh of Plane A

Equation (19) defines the temperature at an interior node of coordinates $i$ and j. Each intersection, as shown in Fig. 2, represents a node of coordinates i, j; i represents the number of nodes from the top and $\mathrm{j}$ represents the number nodes from the cylinder surface. As shown in Eq. (19), the temperature at time step $\mathrm{p}^{+1}$ is determined primarily by the temperatures of the previous time step (p). Once initial conditions and boundary conditions are applied, Eq. (19) can be used to calculate the temperature at each node. The initial conditions that need to be specified are: (a) the dimensions of the processing can, (b) the mass of ceramic waste to be processed, (c) the number of nodes the model should use to accurately represent the process, and (d) the initial temperature. The boundary conditions, that need to be specified, are: (a) ramp up rates, (b) hold temperatures, (c) soak times, and (d) run time of model. 
During the sintering process of the CWF all of the thermophysical properties $\left(k, C_{p}\right.$, and $\left.\rho\right)$, which define thermal diffusivity $(\alpha)$, vary with temperature and with time at temperature. To obtain relationships to approximate waste form density, experimental data was analyzed. The primary source of this density data was experiments conducted at ANL-East by Mark Hash [2]. The symbols in Fig. 3 show the densification data for different temperatures versus soak time.

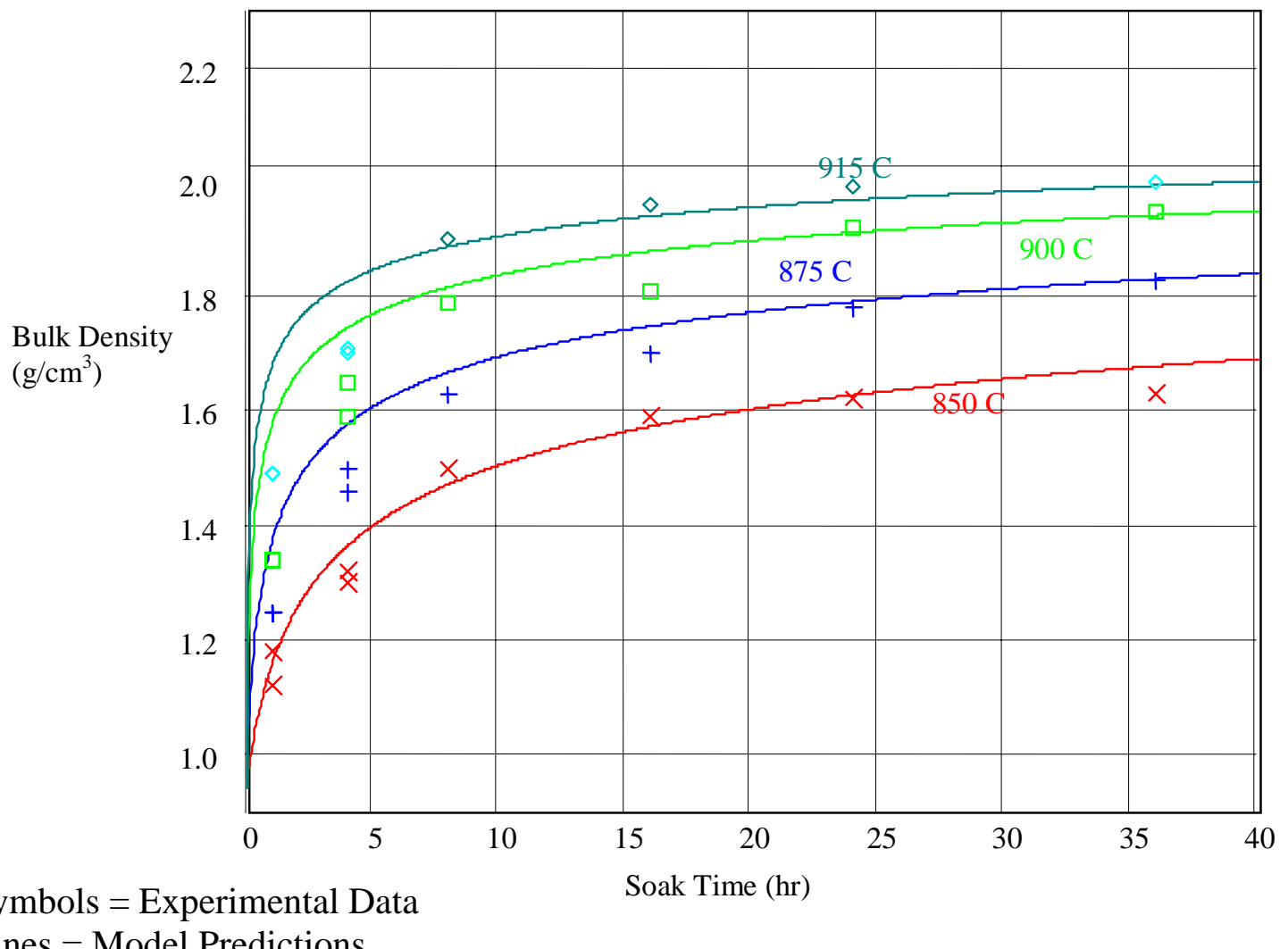

Lines $=$ Model Predictions

Fig. 3. Bulk Density Versus Soak Time for Ceramic Waste Form

Unfortunately, the thermal conductivity $(\mathrm{k})$ and the heat capacity $\left(\mathrm{C}_{\mathrm{p}}\right)$ could not be measured during processing. However, the density $(\rho)$ could be continuously measured using an experimental apparatus utilizing a linear potentiometer, see Fig. 4. By observing how density changed during the sintering process, the behavior of $\mathrm{k}$ and $\mathrm{C}_{\mathrm{p}}$ could be estimated. To match this data, a chemical reaction equation was used. A single species, sixth order reaction converting "species 1" (salt loaded zeolite/glass powder) to "species 2" (consolidated sodalite/glass solid) was fit to the experimental $20 \mathrm{~g}$ sample densities, as is shown by the symbols in Fig. 3 . The equations used to generate the model data, shown as solid lines in Fig. 3, are based on a temperature dependent Arrhenius equation as given by Eq. (20) [6]. 


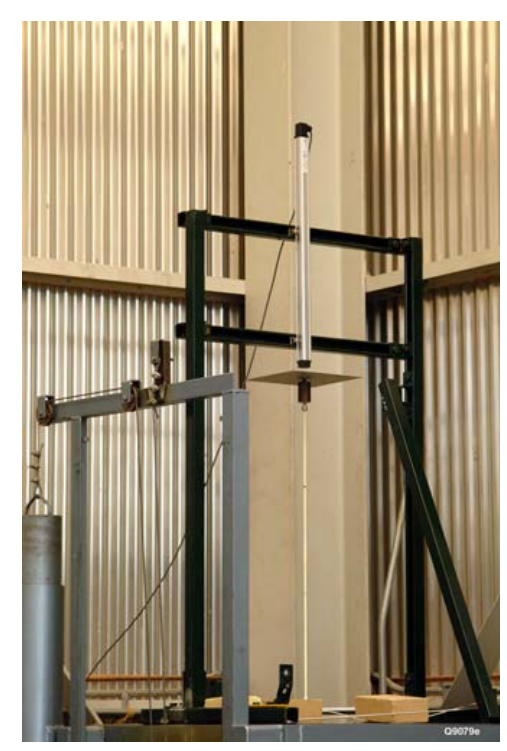

Fig. 4. Experiment Setup of Linear Potentiometer

$$
\rho=\rho_{i} \cdot\left[1+\left(\frac{\rho_{t h}}{\rho_{i}}-1\right) \cdot\left[X_{0}-\left[X_{0}^{1-n}+A_{0} \cdot\left(\frac{T}{K}\right)^{\beta} \cdot \exp \left(\frac{-E_{a}}{T}\right) \cdot t \cdot(n-1)\right]^{\frac{1}{1-n}}\right]\right]
$$

where

$\rho_{i}=$ initial density $\left(\mathrm{kg} / \mathrm{m}^{3}\right)$

$\rho_{t h}=$ theoretical density $\left(\mathrm{kg} / \mathrm{m}^{3}\right)$

$X_{0}=$ initial weight percent of unconsolidated material

$A_{0}=$ rate constant $(1 / \mathrm{s})$

$T$ = temperature $(\mathrm{K})$

$\beta=$ order of temperature

$E_{a}=$ activation energy $(\mathrm{K})$

$t \quad=$ time (s)

$n=$ reaction order

Using the data that best fit the experimental data, the value of rate constant $\left(\mathrm{A}_{\mathrm{O}}\right)$ was $1 \times 10^{-5} \mathrm{~Hz}$, order of temperature $(\beta)$ was 5.159, and activation energy $(E)$ was $3.9 \times 10^{4} \mathrm{~K}$.

Using Eq. (20), the density ( $\rho$ ) can be calculated for each temperature given by Eq. (19). The bulk density can then be calculated by weighting the density at each node by its radial position in the cylinder. The height of the cylinder is then calculated using the average density. Since the height changes, the parameter $\Delta \mathrm{z}$ must also be recalculated at each time step. 
Heat capacity of solids generally follows the convention of varying only with temperature. The sample densities data, the symbols in Fig. 3, suggests that the heat capacity for the CWF is consistent with this general rule [7]. The temperature dependence was found to fit the form shown by Eq. (21).

$$
C_{p}=\frac{a}{T^{2}}+b \cdot T+c
$$

Where a, b, and c are constants found by fitting experimental data. The values of a, b, and c were found to be: $772.318,0.535$, and $-9.494 \times 10^{6}$, respectively.

The thermal conductivity (k) was assumed to vary with temperature and density. The temperature and density dependence are shown by Eq. (22).

$$
k=\frac{\rho_{i} \cdot\left(k_{r e f}-k_{i}\right)}{\rho_{r e f}-\rho_{i}} \cdot \frac{\rho-\rho_{i}}{\rho_{i}}+T \cdot \frac{k_{i n t}-k_{i}}{T_{r e f}-T_{i}}+k_{i}-T_{i} \cdot \frac{k_{i n t}-k_{i}}{T_{r e f}-T_{i}}
$$

where:

$k_{r e f}=$ post processing measured thermal conductivity value $(\mathrm{W} / \mathrm{m} \cdot \mathrm{K})$

$k_{i}=$ initial thermal conductivity value $(\mathrm{W} / \mathrm{m} \cdot \mathrm{K})$

$\rho_{\text {ref }}=$ post processing density, corresponding to $\mathrm{k}_{\mathrm{ref}}\left(\mathrm{kg} / \mathrm{m}^{3}\right)$

$K_{\text {int }}=$ estimated thermal conductivity value at $\mathrm{T}_{\text {ref }}(\mathrm{W} / \mathrm{m} \cdot \mathrm{K})$

$T_{\text {ref }}=$ softening point of the glass in ceramic $(\mathrm{K})$

$T_{i}=$ initial temperature $(\mathrm{K})$

The initial value of thermal conductivity of $0.135 \mathrm{~W} / \mathrm{m} / \mathrm{K}$ was obtained from experiments performed by Purdue University[7]. The softening point, or transition point, of the glass is the temperature were the glass begins to soften. For the glass used in these experiments, this value was $567^{\circ} \mathrm{C}$. Up to the transition point, the value for thermal conductivity was set in the model to increase linearly to 1.5 times the initial value. After the transition point was reached, the value was set to increase proportionally with the calculated density. The value continued to increase until the thermal conductivity reached a maximum of $1.4 \mathrm{~W} / \mathrm{m} / \mathrm{K}$, corresponding with a calculated density of $2 \mathrm{~g} / \mathrm{cm}^{3}$. Setting the boundary temperature and then solving for time at temperature related properties, the model solved Eq. (19) to predict material temperature as a function of location, and Eq. (20) was used to predict densification. 


\section{Model 1 Results}

The results of Model 1 may primarily be used to address criteria with the overall design. The criteria addressed include optimal production-scale processing size, the affect processing size has on heat up and soak times, and optimal can dimensions for production-scale processing. The optimal radius of the CWF storage can is approximately 10.2 in. $(25.9 \mathrm{~cm})$. Using the fixed radius and setting the bulk density equal to the initial and the final bulk densities, the model can solve for the bounding heights of a CWF canister (Fig. 5). The graph depicts the fact that the when the final density value was used, a shorter cylinder height will be needed to contain the CWF. The graph also illustrates the range of possible can heights needed for production-scale processing.

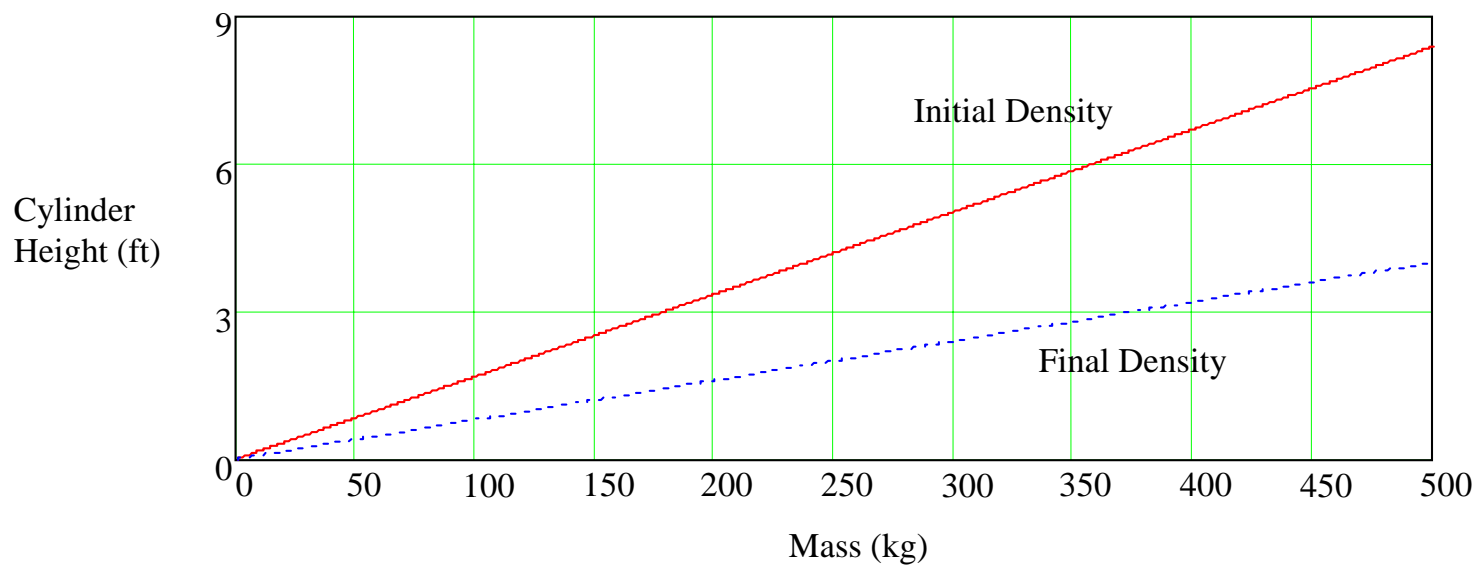

Fig. 5. Height of Production Canister Versus Ceramic Waste Form Mass

Fig. 6 shows the core temperature (using all initial thermophysical properties) versus mass of the CWF for different soak times at $915^{\circ} \mathrm{C}$. The graph represented in Fig. 6 indicates that for masses greater than $200 \mathrm{~kg}$, the core temperature is independent of mass. Since radius is held constant, once a certain mass/height is attained, the core is heated almost entirely from the sides; i.e., radially. For masses greater than $200 \mathrm{~kg}$, the temperature cycle required is independent of mass.

Fig. 7 shows the difference in core heating profiles using final values of $k, \rho$, and Cp. Similar data is presented using initial values of $k, \rho$, and Cp. As illustrated in Fig. 7, the temperature cycle required to allow the core to reach $800^{\circ} \mathrm{C}$ ranges from $12 \mathrm{~h}$ to $70 \mathrm{~h}$. The actual core heat up time will be between these two extremes, depending on how and when the thermophysical properties change. 


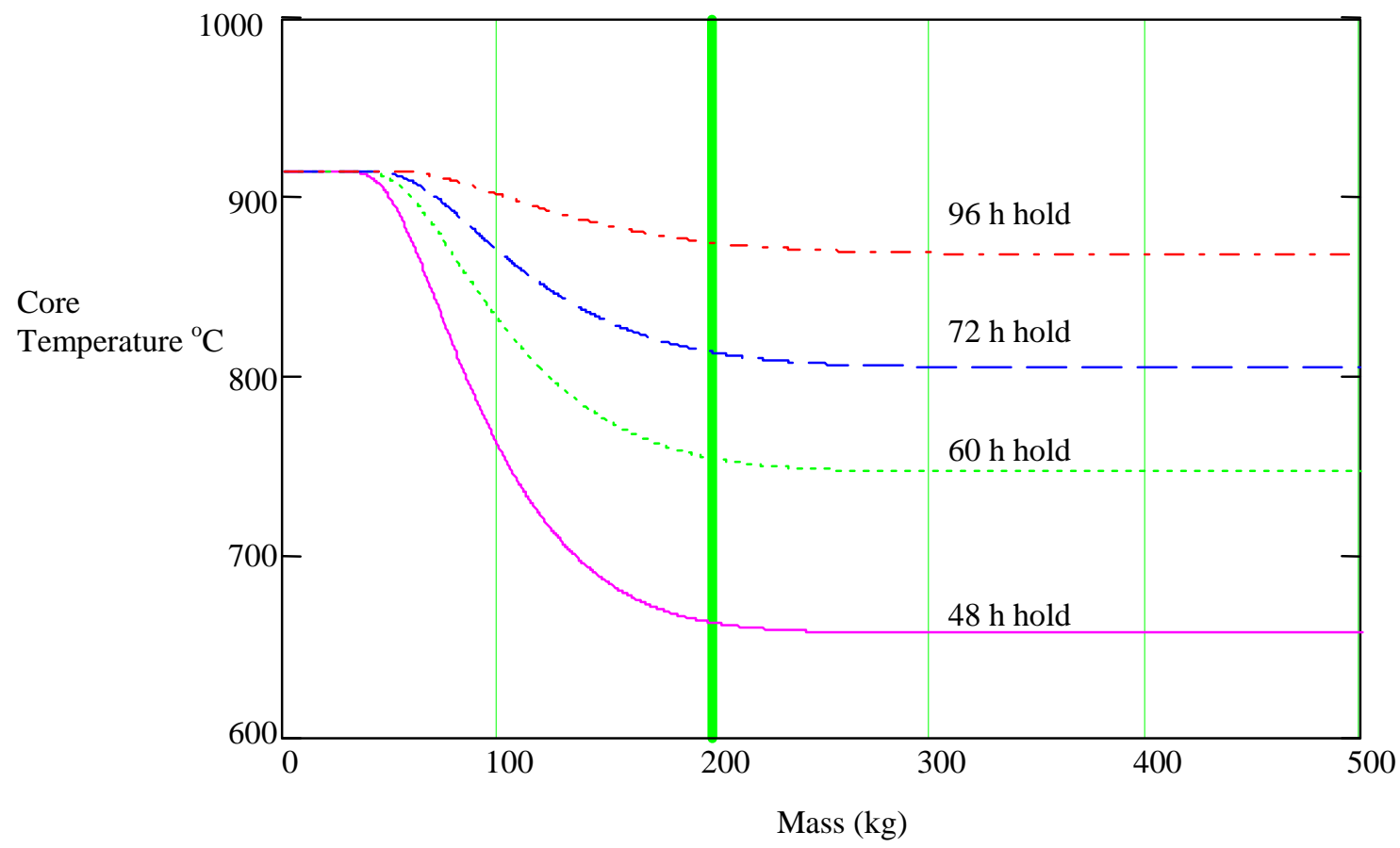

Fig. 6. Ceramic Waste Form Temperature Versus Mass

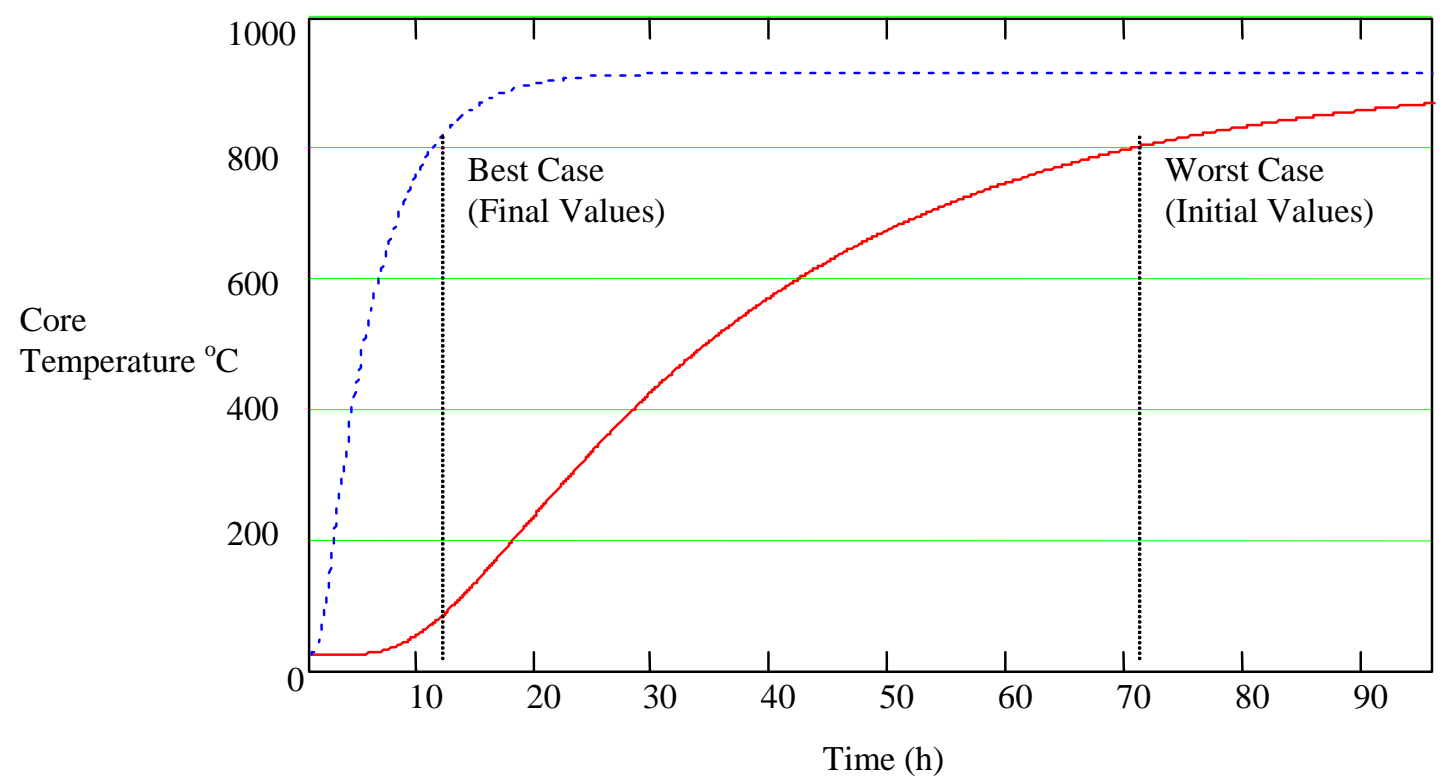

Fig. 7. Production Size Ceramic Waste Form Core Temperature Versus Time 


\section{Model 2 Results}

Model 2 was developed to provide temperature profiles and densification data to correlate with experimental data. Fig. 8 and Fig. 9 illustrate the temperature profiles and densification predictions for a $25 \mathrm{~kg}$ CWF, respectively.

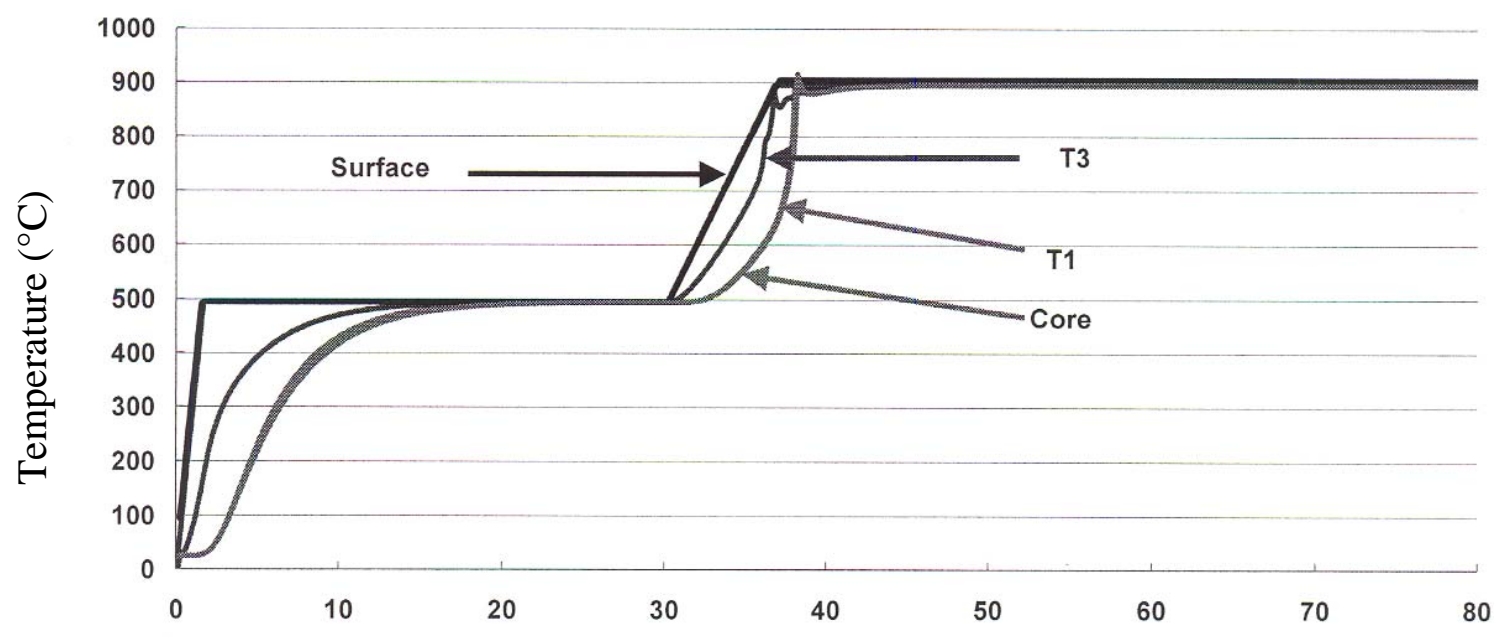

Time (h)

Fig. 8. Temperature Versus Time for 25 kg Ceramic Waste Form Model

Fig. 8 shows the predictions for temperatures at the thermocouple (TC) locations used in the $25 \mathrm{~kg}$ experiment. As shown in Fig. 1a, T1 represents the temperature $15.25 \mathrm{~cm}$ up from the can bottom in the radial center of the can. T3 represents the temperature $15.25 \mathrm{~cm}$ up from the can bottom and $8.9 \mathrm{~cm}$ from the radial center of the can. The surface temperature was the set-point temperature used by the furnace controller. The core temperature was a prediction of the temperature of the core of the material and moved during consolidation. There was no thermocouple in the experiment to track this temperature. This data indicates that the "true" moving core temperature, which would be difficult to track during an experiment, could be represented with a fixed center thermocouple during the experiment. The model also depicts the gradient that exist radially and also shows an exothermic reactions in all locations. 


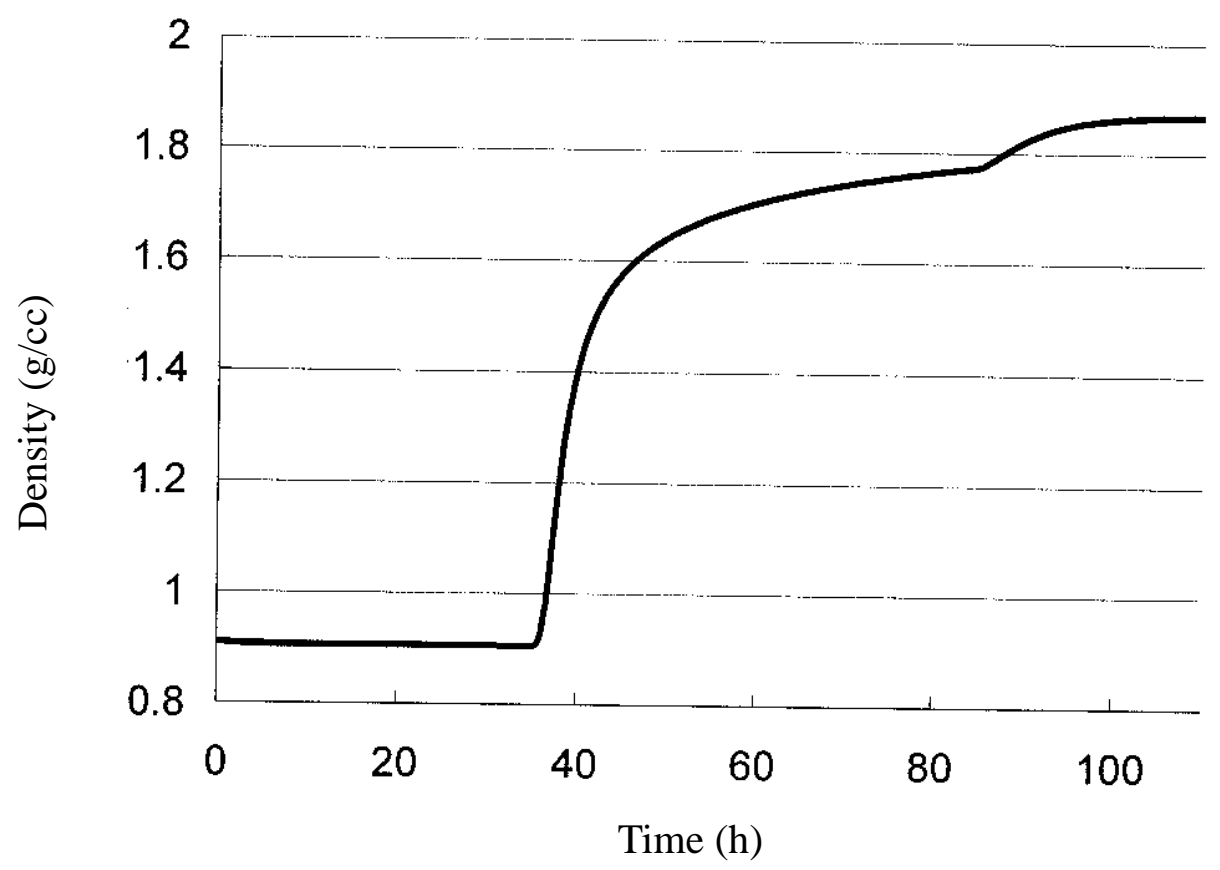

Fig. 9. Bulk Density Versus Time for the 25 kg Ceramic Waste Form Model

Fig. 9 shows the bulk density versus time predicted by the model. It is important to note that the density represented is an average density, not a point density. An average density is desired as it can be compared to experimental results obtained from the linear potentiometer. During the first 35 hours no increase in density was observed. Initial densification occurred rapidly, then asymptotically approached the maximum density. As can be seen at around 80 hours, cooling also produced a density increase due to the thermal contraction of the material.

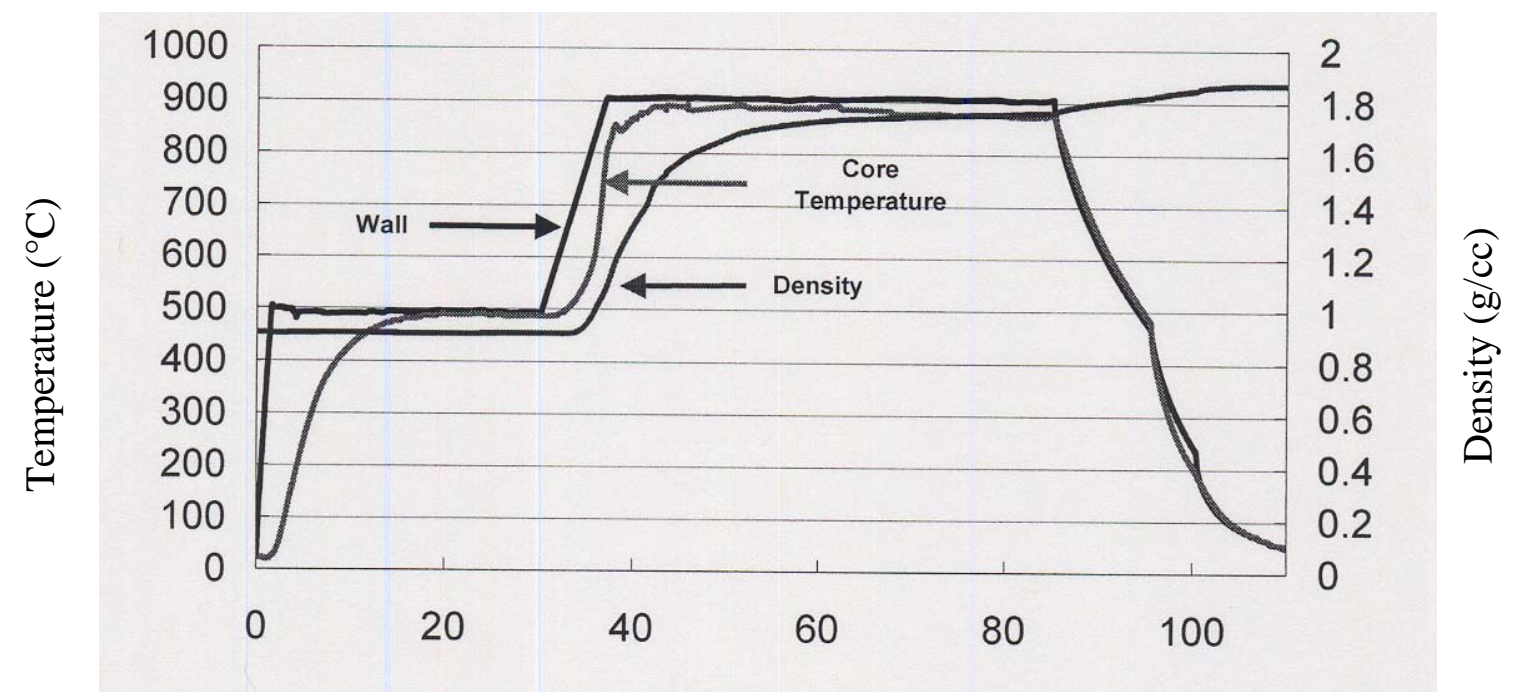

Time (h)

Fig. 10. Experimental Data from 25 kg Ceramic Waste Form Experiment 
The temperature and density data obtained from a $25 \mathrm{~kg}$ CWF experiment is illustrated in Fig. 10. The two temperature readings refer to thermocouples placed on the wall of the canister and in the radial center (TC1) of the canister. The density plot was obtained by using the linear potentiometer readings to calculate height and bulk density. The data from the experiment can be plotted with the model data and the accuracy of Model 2 can be observed. This overlay of data is shown in Fig. 11 and Fig. 12. Figure 11 shows the temperature overlays, while Fig. 12 shows the density overlays. As is shown in Fig. 11, the model accurately predicts the initial heat up to $500^{\circ} \mathrm{C}$. During this part of the experiment, any remaining moisture was driven off as the material is heated. The model assumption of $150 \%$ increase in the thermal conductivity seems to be validated. During the $500^{\circ} \mathrm{C}$ soak, the temperature of material equalized; this is accurately reflected by the model. After the soak, the prediction by the model correlates as temperature increases, however, using the current parameters, the model was unable to predict the rapid heating associated with the exothermic reaction. The overall modeled trend, however, is representative of the experimental results.

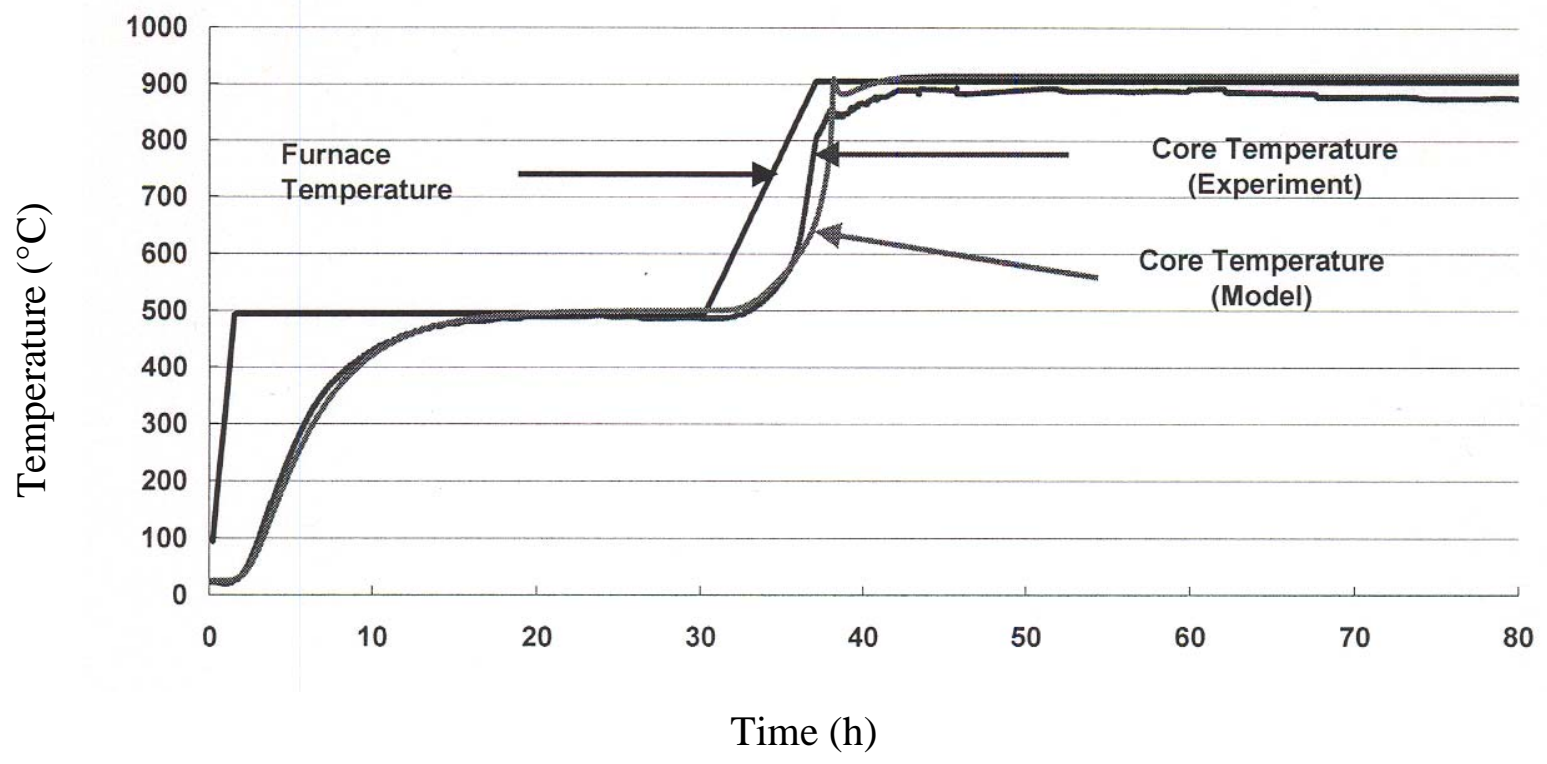

Fig. 11. Comparison of Model 2 Versus 25 kg Experimental Temperature Data 


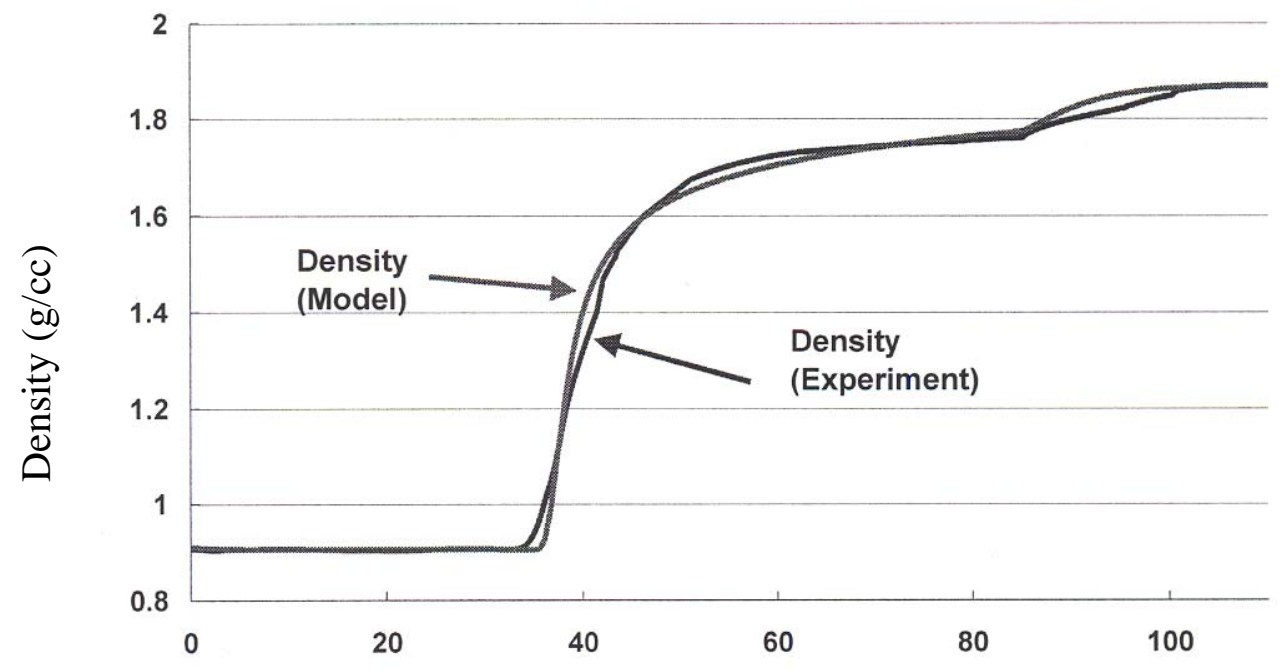

Time (h)

Fig. 12. Comparison Model 2 Versus 25 kg Experimental Bulk Density Data

Fig. 12 shows comparisons between the model's predictions of bulk density and the actual experimental data. As the material was heated, both the modeled and the experimental data remained at constant density. The model accurately tracked the rapid densification as the bulk temperature approached $567^{\circ} \mathrm{C}$. The model continues to track the experiment during the long $915^{\circ} \mathrm{C}$ hold. The model also appeared to predict the thermal contraction of the material as it cooled at around $80 \mathrm{~h}$. The model predicted a final density of $1.85 \mathrm{~g} / \mathrm{cm}^{3}$, whereas the experiment yielded a final density of $1.87+/-0.02 \mathrm{~g} / \mathrm{cm}^{3}$.

An experimental setup similar to the $25 \mathrm{~kg}$ sample was used to produce a $140 \mathrm{~kg}$ sample. The results of the model are compared to the experimental data in Fig. 13 and Fig. 14. The temperature plot (Fig. 13) shows data from a center thermocouple, located 6.2 in. from the bottom of the canister. As is shown, the model again looks very similar to the experimental data. At around 150 hours, an exothermic reaction created a spike in temperature. The model and the experiment behaved the same. 


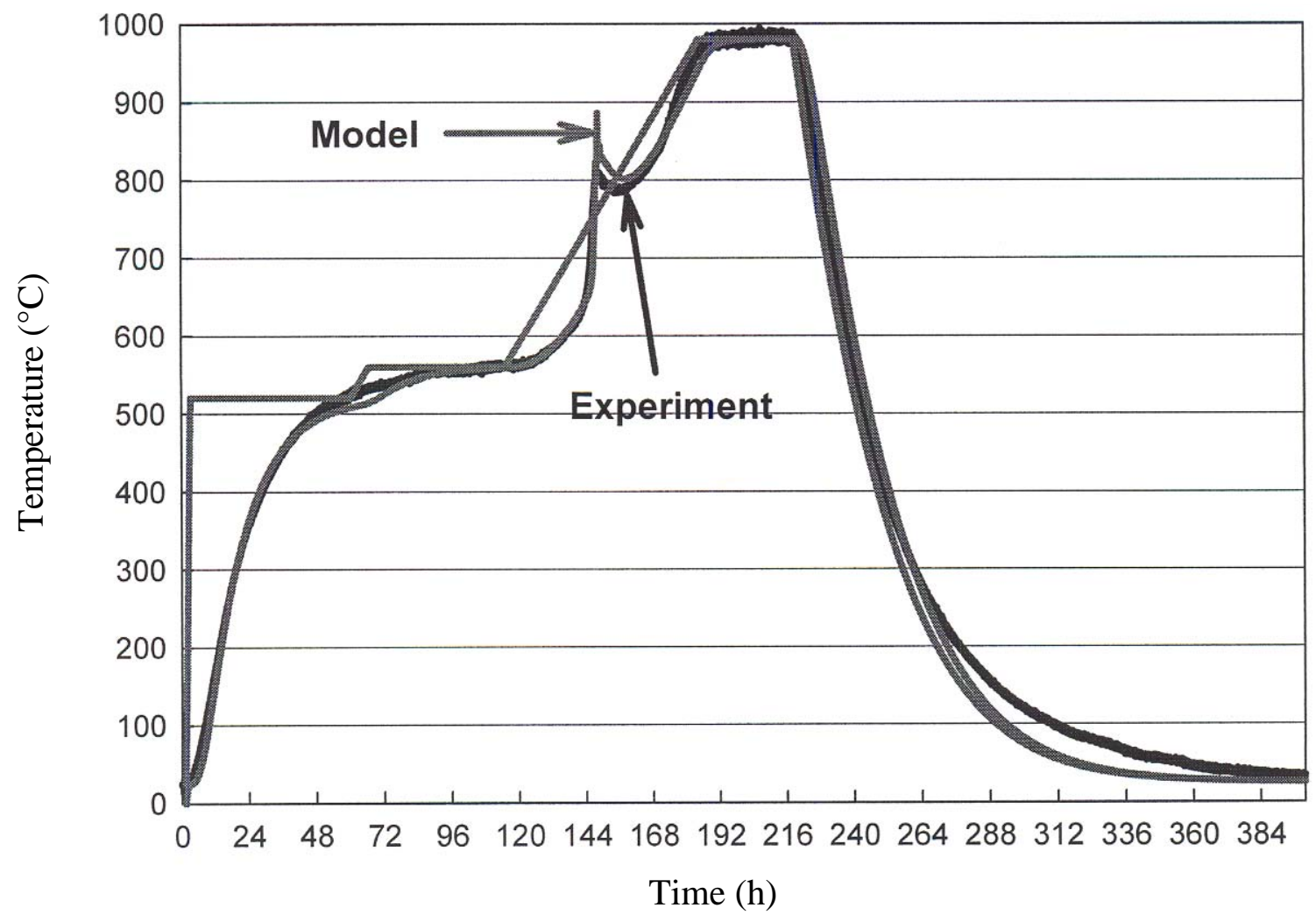

Fig. 13. Comparison of Model 2 Versus 140 kg Experimental Temperature Data

Fig. 14 shows that the model accurately predicted the general trends observed in the experimental density data. There appears to be a slight offset between the two sets of data. This deviation is most obvious in the data during the material heated up. The model shows that there was no increase in density, however, the experiment records a slight increase. This increase can be attributed to the thermal expansion of the $200 \mathrm{~kg}$ of steel that was used to maintain an inert environment. The model predicted the final bulk density to be $2.0 \mathrm{~g} / \mathrm{cm}^{3}$. The measured bulk density was $1.98+/-0.02 \mathrm{~g} / \mathrm{cm}^{3}$. 


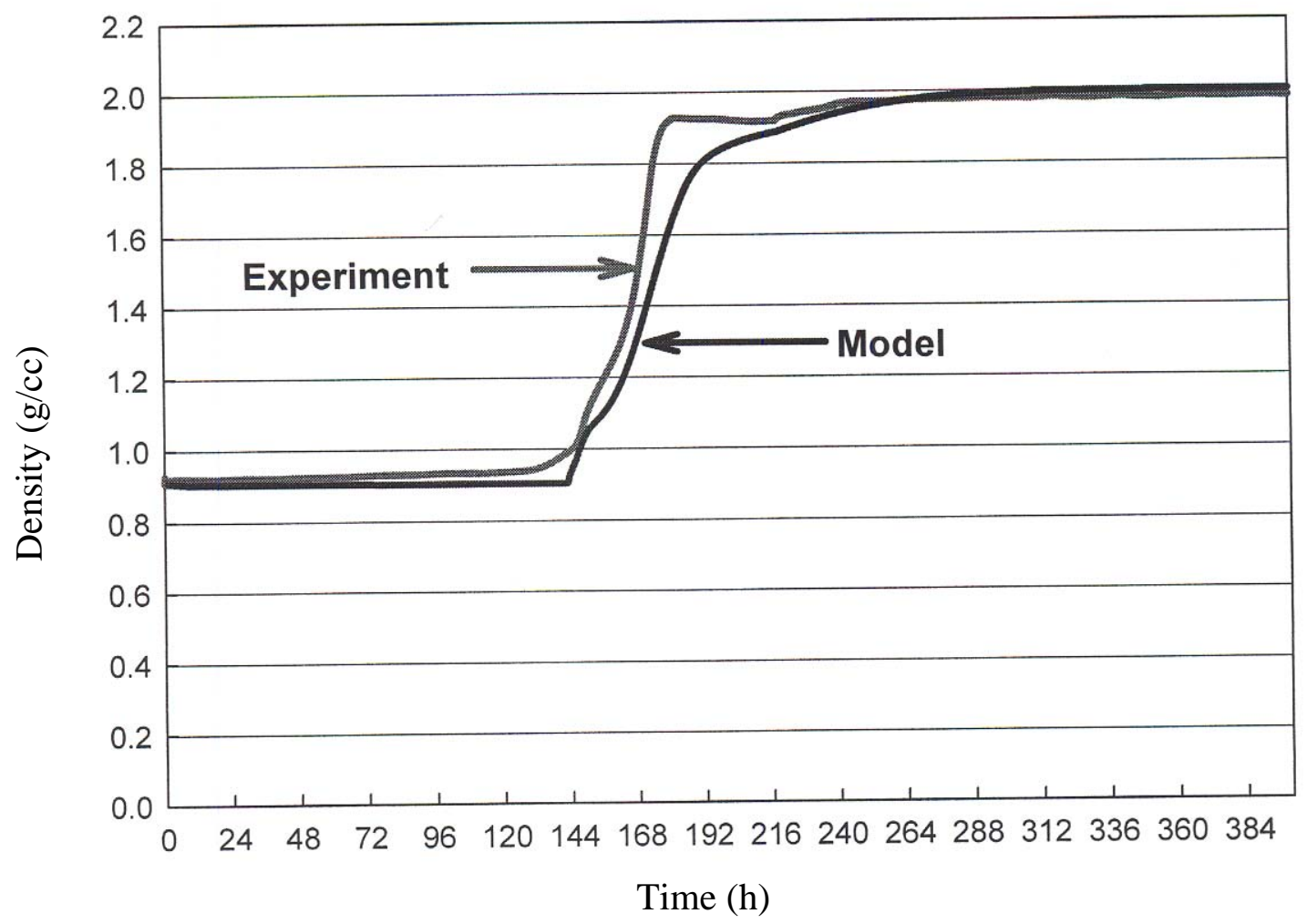

Fig. 14. Comparison of Model 2 Versus 140 kg Experimental Bulk Density Data

\section{Conclusions}

The results of the comparison between the experiments and model are very promising. The results from the first model bounded the canister height for a $200 \mathrm{~kg}$ CWF between $0.5 \mathrm{~m}$ to $1.0 \mathrm{~m}$ and bounded the hold time for the same mass between 12 and $70 \mathrm{~h}$. The required hold time at maximum temperature for masses above $200 \mathrm{~kg}$ was shown to remain constant. The second model included variables that varied with temperature and time at temperature. The data from this model was found to accurately represent temperature trends observed within experimental CWFs. Additionally, the data was within $1 \%$ of the data for the bulk density of experimental CWFs up to $140 \mathrm{~kg}$. The models were useful in determining processing conditions of CWFs and will continue to be a valuable tool during the scale-up CWFs.

\section{ACKNOWLEDGMENT}

This work was supported by the U. S. Department of Energy, Office of Nuclear Energy, Science and Technology, under Contract W-31- 109-Eng-38 with the University of Chicago as operator of Argonne National Laboratory. 


\section{REFERENCES}

1. K. M. Goff, R. W. Benedict, K. J. Bateman, M. A. Lewis, C. Pereira, and C. A. Musick, “Spent Fuel Treatment and Mineral Waste Form Development at Argonne National Laboratory-West,” 3:2436, American Nuclear Society, International Topical Meeting On Nuclear And Hazardous Waste Management, Seattle, WA (August 18-23, 1996).

2. M. C. Hash, A. S. Hebden, N. L. Stephenson, and M. Foubert to Distribution, Argonne National Laboratory-East, personal communication (July 2000).

3. MathCad 2001 is a registered trademark of Mathsoft, Inc., Copyright (C) 1986-2001, Cambridge, MA (2001).

4. F. P. Incropera and D. P. DeWitt, Fundamentals of Heat and Mass Transfer, $4^{\text {th }}$ ed., 229-230, 243- 244, John Wiley \& Sons, Inc., New York, NY (1996).

5. F. P. Incropera and D. P. DeWitt, Fundamentals of Heat and Mass Transfer, $4^{\text {th }}$ ed., 248-249, John Wiley \& Sons, Inc., New York, NY (1996).

6. O. Levenspiel, Chemical Reaction Engineering, $2^{\text {nd }}$ ed., 50-51, John Wiley \& Sons, Inc., New York, NY (1972).

7. “Thermophysical Properties of Seven Ceramic Materials" Thermophysical Properties Research Laboratory, Inc. Report (March 2001). 


\section{APPENDIX A}

Note: All inputs should include units where appropriate.

$C:=\mathrm{K} \quad \mathrm{Kel}:=273.15 \cdot \mathrm{K}$

\section{User Inputs; Physical Properties}

Initial Density, found by initial measurements

$\rho_{\mathrm{i}}:=.91 \cdot \frac{\mathrm{gm}}{3}$

Ket vensity, rrom TPRL Softening point of glass

from manufacturer specs

repor, represents

fit data

$\rho_{\text {ref }}:=2 \cdot \frac{\mathrm{gm}}{\mathrm{cm}^{3}} \quad \mathrm{~T}_{\text {ref }}:=567 . \mathrm{C}$

Container Radius Mass of material,

measured value measured value

$R:=\frac{20.9}{2}$. in $\quad M:=140.21 \cdot \mathrm{kg}$

End of model $\quad \begin{aligned} & \text { Generation Tem } \\ & \text { qdot }=3.768\end{aligned}$

tend $:=400 \cdot h$ $\begin{array}{ll}\text { Initial thermal conductivity, has some } & \begin{array}{l}\text { Theoretical Density } 2.3 \text { for } \\ \text { variation but between .1 and .14 }\end{array} \\ \text { good material, MFD-02 is } 2.15\end{array}$

$$
\mathrm{k}_{\mathrm{i}}:=.135 \cdot \frac{\mathrm{W}}{\mathrm{m} \cdot \mathrm{K}} \quad \rho_{\text {th }}:=2.15 \cdot \frac{\mathrm{gm}}{\mathrm{cm}^{3}}
$$

Coefficient of therma

expansion from TPRL

\section{Coefficient of heat transfer}

during cool down, varies by fumace

Ref thermal conductivity, at reference density bren

$$
\mathrm{k}_{\mathrm{ref}}:=1.4 \frac{\mathrm{W}}{\mathrm{m} \cdot \mathrm{K}} \quad \mathrm{P}_{\mathrm{atm}}:=12 \cdot \mathrm{psi}
$$

User Inputs; Model Properties

$$
h:=21 \cdot \frac{\mathrm{W}}{\mathrm{m}^{3} \cdot \mathrm{K}}
$$

better accuracy and

counter begins at zero

nitial temperature Final temperature First hold temperature Furnace ramp up rate to Tint$$
a ;=7
$$

$T_{i}:=25 \cdot C$

$\mathrm{T}_{\mathrm{f}}=\mathbf{9 8 0 . \mathrm { C }} \quad \mathrm{T}_{\mathrm{int}}=560 \cdot \mathrm{C}$

$$
\mathrm{T}_{\mathrm{r} 1}:=5 \cdot \frac{\mathrm{C}}{\mathrm{min}}
$$
$\begin{array}{lcccc}\begin{array}{l}\text { Generation }=3.768 \\ \text { qdorm }\end{array} & \text { Furnace ramp up rate to } \mathrm{Tf} \text { Hold time at Tint } & \text { Furnace hold time at } \mathrm{Tf} & \begin{array}{l}\text { Heat of Reaction Constants } \mathrm{Hr} 1 \text { sets } \\ \text { magnitude of heat, } \mathrm{xHr} \text { sets rate of descent, }\end{array}\end{array}$

Furnace hold time at $\mathrm{Tf} \quad$ Heat of Reaction Constants $\mathrm{Hr} 1$ sets

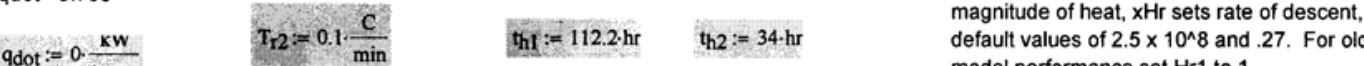

$$
\text { qdot: }=0 \text { tonne }
$$

Coordinates for set Point Temperatures

TC 1 Ra1 is distance from

TC $2 \mathrm{Ra} 2$ is distance from radial center, $\mathrm{Z} 2$ is height radial center, $Z 1$ is heir

$\mathrm{Ra} 2:=0$-in

$\mathrm{Z2}:=6.2$ in

\section{Ral $:=0$-in $\quad \mathrm{Zl}:=3$.}

Preexponetial rate constan

$$
\mathrm{k}_{1}:=1 \times 10^{-5} \mathrm{~Hz}
$$

\section{Activation Energy/Universal gas constant}

$$
E_{1}:=3.942 \times 10^{4} \mathrm{~K}
$$

Note: All reaction constants $(k 1, E 1, n g, \beta g)$ are derived in Mathcad work sheet "constants", Cp coefficients are found in work sheet "Cp curve fit"

$$
\begin{aligned}
& \text { Intermediate thermal conductivity } \\
& \text { (Guessed value of } k \text { at Tref) } \\
& k_{\text {int }}:=1.6 \cdot \mathrm{k}_{\mathrm{i}} \\
& \mathrm{H}_{\mathrm{r} 1}:=1.25 \cdot 10^{8} \quad \mathrm{x}_{\mathrm{H}}:=.27 \\
& \text { Order of Reaction Order of temperature Coefficients of heat capa } \\
& \mathrm{n}_{\mathrm{g}}:=5.323 \quad \beta_{\mathrm{g}}:=5.159 \quad \mathrm{c}:=\left(-9.49410^{6} .535\right.
\end{aligned}
$$

\section{Order of Reaction$$
\mathrm{n}_{\mathrm{g}}:=5.323
$$$$
\beta_{g}:=5.159
$$

model performance set $\mathrm{Hr} 1$ to 1 .

\section{Calculations:}

Cylinder Height

$H:=\frac{M}{\pi \cdot R^{2} \cdot \rho_{i}} \quad \begin{array}{ll}H=27.407 \text { in } \\ H=2.284 \mathrm{ft}\end{array}$

Density of $1 \%$ Carbon Stee

$$
\rho C S:=7800 \frac{\mathrm{kg}}{\mathrm{m}^{3}} \quad \rho C S=0.282 \frac{\mathrm{lb}}{\mathrm{in}^{3}}
$$

Number of vertical nodes

$\mathrm{b}:=$ floor $\left(\mathrm{a} \cdot \frac{\mathrm{H}}{\mathrm{R}}\right) \quad \mathrm{b}=18$


Mass of Plug

$$
\mathrm{MP}:=\mathrm{PH} \cdot \rho \mathrm{CS} \cdot\left(\pi \cdot \mathrm{R}^{2}\right) \quad \begin{aligned}
& \mathrm{MP}=155.614 \mathrm{~kg} \\
& \mathrm{MP}=343.07 \mathrm{lb}
\end{aligned}
$$

Set Fourier number,

for stability needs to

be less than .25

$$
\text { Fo }:=\frac{1}{5}
$$

Initial mass percent of zeolite/glass

$$
\mathrm{X}_{0}:=1
$$

Factor of $k$ dependence on density,

Doug's magic

Total \# of nodes

fac $:=\frac{\rho_{i} \cdot\left(k_{\text {ref }}-k_{i}\right)}{k_{i} \cdot\left(\rho_{\text {ref }}-\rho_{i}\right)}$

$$
\begin{gathered}
a b:=(a+1) \cdot(b+1) \quad a b=152 \\
f a c=7.823
\end{gathered}
$$

Temperature Initial Condition set to $\mathrm{Ti}$

Range Variables

$$
\mathrm{T}_{\mathrm{ic}} \mathrm{i}, \mathrm{j}_{\mathrm{i}}:=\mathrm{T}_{\mathrm{i}}
$$

Weight factor for averaging radial nodes to represent a 3D model
Temperature dependent slope and intercept of $\mathbf{k}$

$$
\mathbf{s l}:=\frac{\mathbf{k}_{\text {int }}-\mathbf{k}_{\mathbf{i}}}{\mathrm{T}_{\text {ref }}-\mathrm{T}_{\mathbf{i}}} \quad \text { int }:=\mathrm{k}_{\mathbf{i}}-\mathbf{s l} \cdot \mathrm{T}_{\mathbf{i}}
$$

Distance between radial nodes

Distance between axial nodes (initially)

$\Delta r:=\frac{R}{a} \quad \Delta r=1.493$ in $\quad \Delta z:=\frac{H}{b} \quad \Delta z=1.523$ in

Thermal Diffusivity Initially

Radial distance of node $\mathrm{j}$ from core

$$
\alpha_{i}:=\frac{k_{i}}{\left[c_{1} \cdot\left(\frac{T_{i}+K e l}{K}\right)^{-2}+c_{1} \cdot \frac{T_{i}+K e l}{K}+c_{1}\right] \cdot \rho_{i}}
$$$$
\mathbf{r}_{\mathbf{j}}:=\mathrm{R}-\mathrm{j} \cdot \Delta \mathbf{r}
$$

$\alpha_{i}=1.798 \times 10^{-7} \frac{\mathrm{m}^{2}}{\mathrm{~s}}$

$\stackrel{\sim}{\sim}$

$$
\left.A_{0}:=\pi \cdot\left[R^{2}-\left(R-\frac{\Delta r}{2}\right)^{2}\right] \quad i:=1 . . \mathrm{a}-1 \quad A_{i}:=\pi \cdot\left(r_{i}+\frac{\Delta r}{2}\right)^{2}-\left(r_{i}-\frac{\Delta r}{2}\right)^{2}\right] \quad A_{a}:=\pi \cdot\left(\frac{\Delta r}{2}\right)^{2} \quad \quad \quad \operatorname{rat}_{r_{j}}=\frac{A_{j}}{\Delta A} \cdot(2 \cdot a)^{2}
$$

Weight factor for averaging axial nodes to represent a 3D model

$$
\operatorname{rat}_{z_{0}}:=1 \quad \lambda:=1 . . \mathrm{b}-1 \quad \operatorname{rat}_{\mathrm{z}_{\lambda}}:=2 \quad \operatorname{rat}_{\mathrm{z}_{\mathrm{b}}}:=1
$$

$$
\begin{aligned}
& \text { Time step } 1 \quad \text { Total time Time furnace reaches Tint Time furnace starts ramp }
\end{aligned}
$$

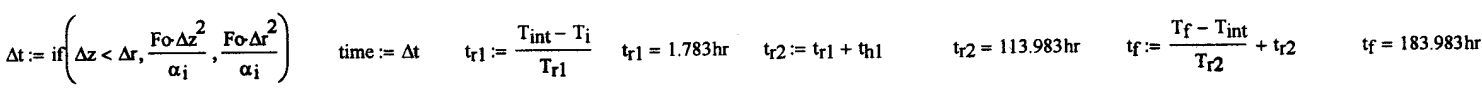

Time furnace starts cool down

$t_{c}:=t_{f}+t_{h}$

$t_{c}=217.983 \mathrm{hr}$

$\mathrm{k}_{0}:=\frac{\text { Rate constant }}{\left[\mathrm{k}_{1} \cdot\left(\frac{\mathrm{T}_{\mathrm{ic}}+\mathrm{Kel}}{\mathrm{K}}\right)^{\beta_{\mathrm{g}}} \cdot \exp \left(\frac{-\mathrm{E}_{1}}{\mathrm{~T}_{\mathrm{ic}}+\mathrm{Kel}}\right)\right]} \quad \mathrm{X}:=\left[\mathrm{x}_{0}^{1-\mathrm{n}_{\mathrm{g}}}+\mathrm{k}_{0} \cdot \Delta \mathrm{t} \cdot\left(\mathrm{n}_{\mathrm{g}}-1\right)\right]^{\frac{1}{1-\mathrm{n}_{\mathrm{g}}}}$
Diameter

Number of elements

$\mathrm{D}:=2 \cdot \mathrm{R}$

$$
\text { mum }:=a \cdot b \quad \text { mum }=126
$$

Surface temperature

$T_{\mathbf{s}}:=\operatorname{if}\left(\right.$ time $\left.<t_{f}, T_{i}+T_{r 1} \cdot t_{\text {time }}, T_{f}\right)$

Mass Percent of Zeolite Glass

$$
\rho:=\frac{\text { Density }}{\left[\frac{\rho_{i}}{\beta \cdot\left(T_{i c}-T_{i}\right)+1}\left[1+\left(\frac{\rho_{\text {th }}}{\rho_{i}}-1\right) \cdot(1-X)\right]\right]}
$$


Thermal conductivity

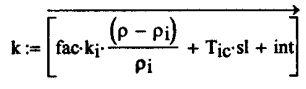

$$
\mathrm{C}_{\mathrm{p}}:=\underset{\left[\mathrm{c}_{\mathrm{l}_{0}} \cdot\left(\frac{\mathrm{T}_{\mathrm{ic}}+\mathrm{Kel}}{\mathrm{X}}\right)^{-2}+\mathrm{ct}_{1} \cdot \frac{\mathrm{T}_{\mathrm{ic}}+\mathrm{Kel}}{\mathrm{K}}+\mathrm{c}_{2}\right]}{\text { Heat Capacity }}
$$

$$
\rho_{\text {ave }}=\frac{\sum_{j=0}^{a} \sum_{i=0}^{b} \rho_{i, j}, \text { rat }_{r j} \text { rat }_{i j}}{\sum_{j=0}^{a} \sum_{i=0}^{b} \operatorname{ratr}_{j} \text { rat }_{i}} \quad \rho_{a v e}=910 \frac{\mathrm{kg}}{\mathrm{m}^{3}}
$$

$$
\Delta:=\frac{H}{b} \quad \alpha:=\frac{\vec{k}}{\rho \cdot C_{p}}
$$

Temperature, density, heat capacity, thermal conductivity, height, etc. will be recalculated at each time step until tend is reached using the following hidden program.

N

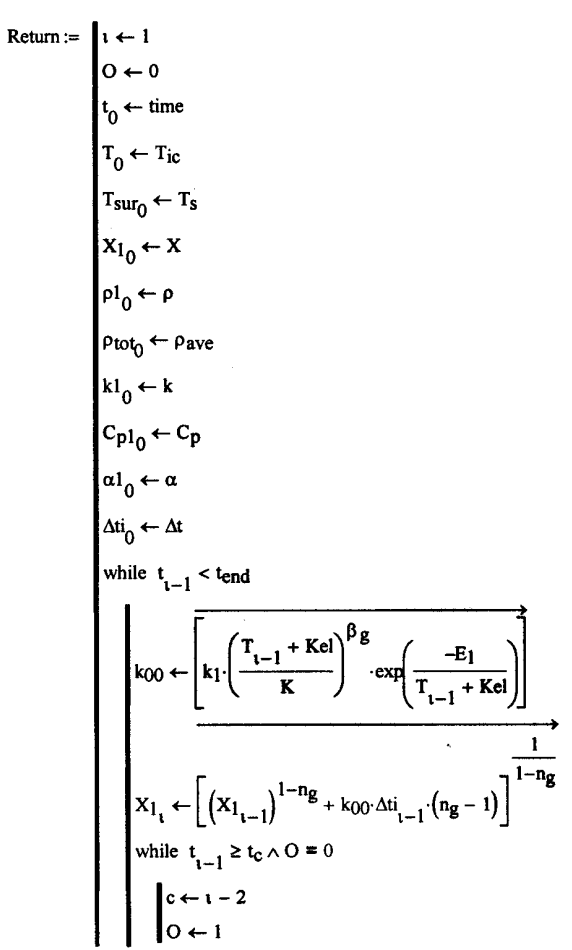




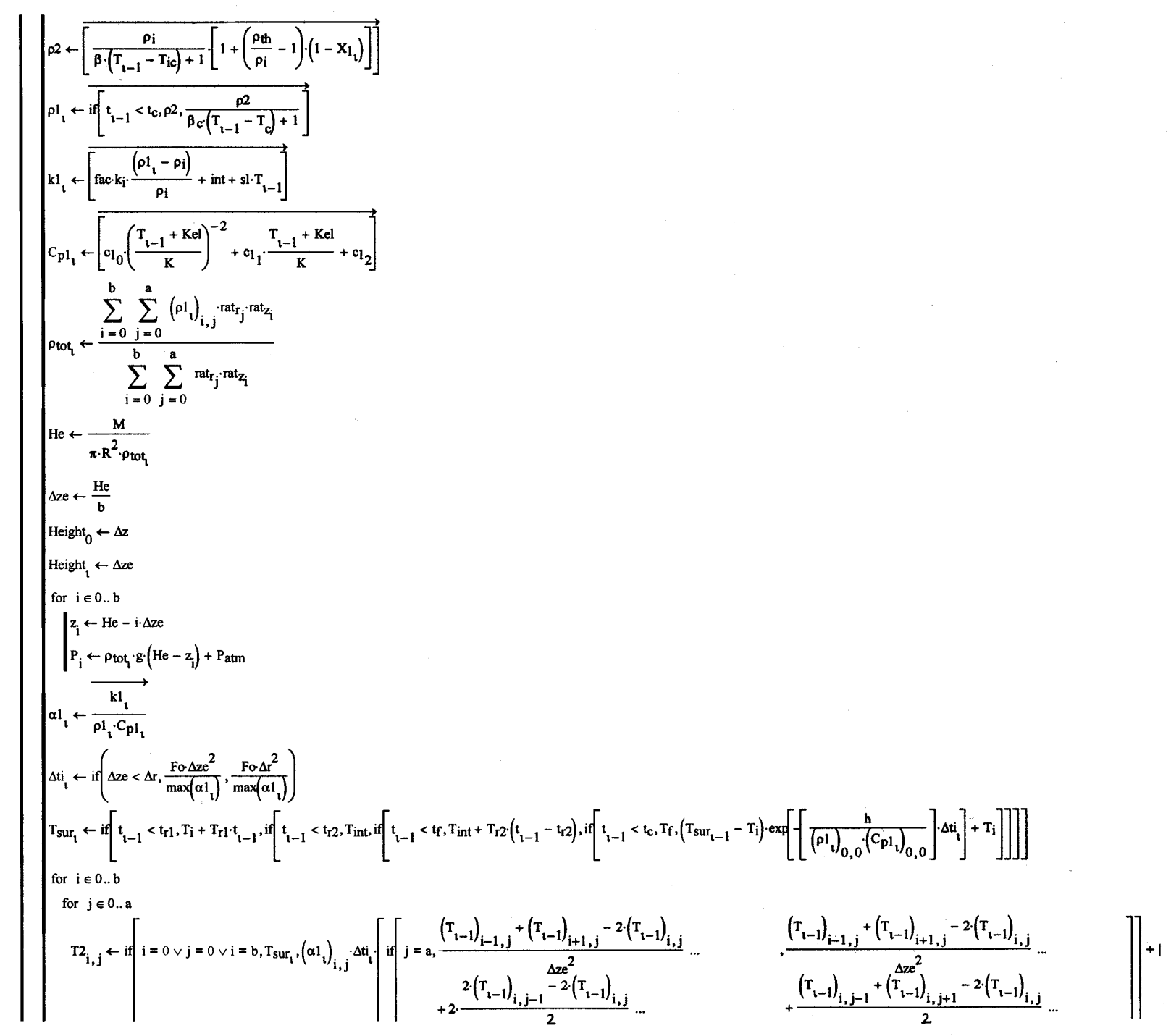




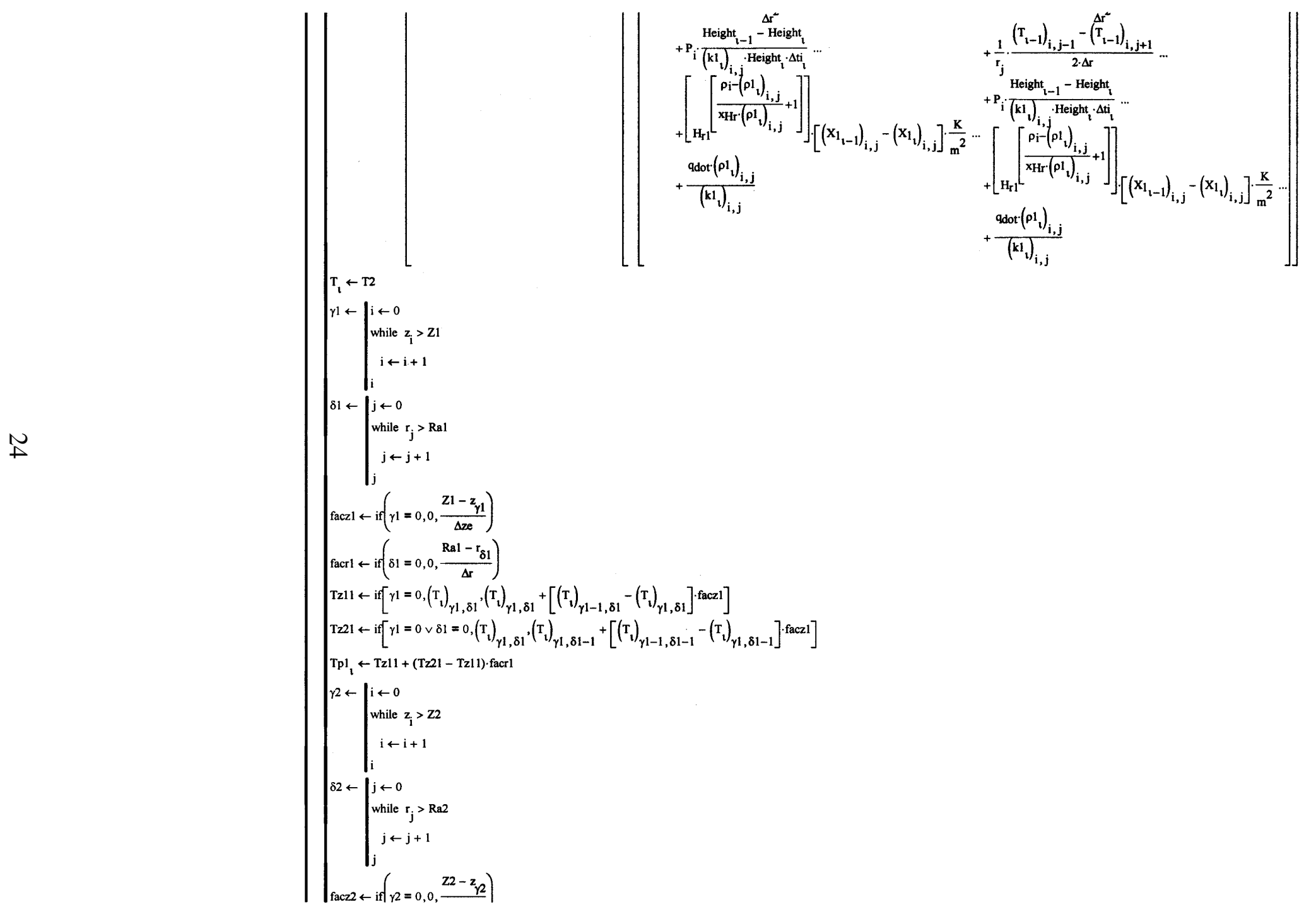




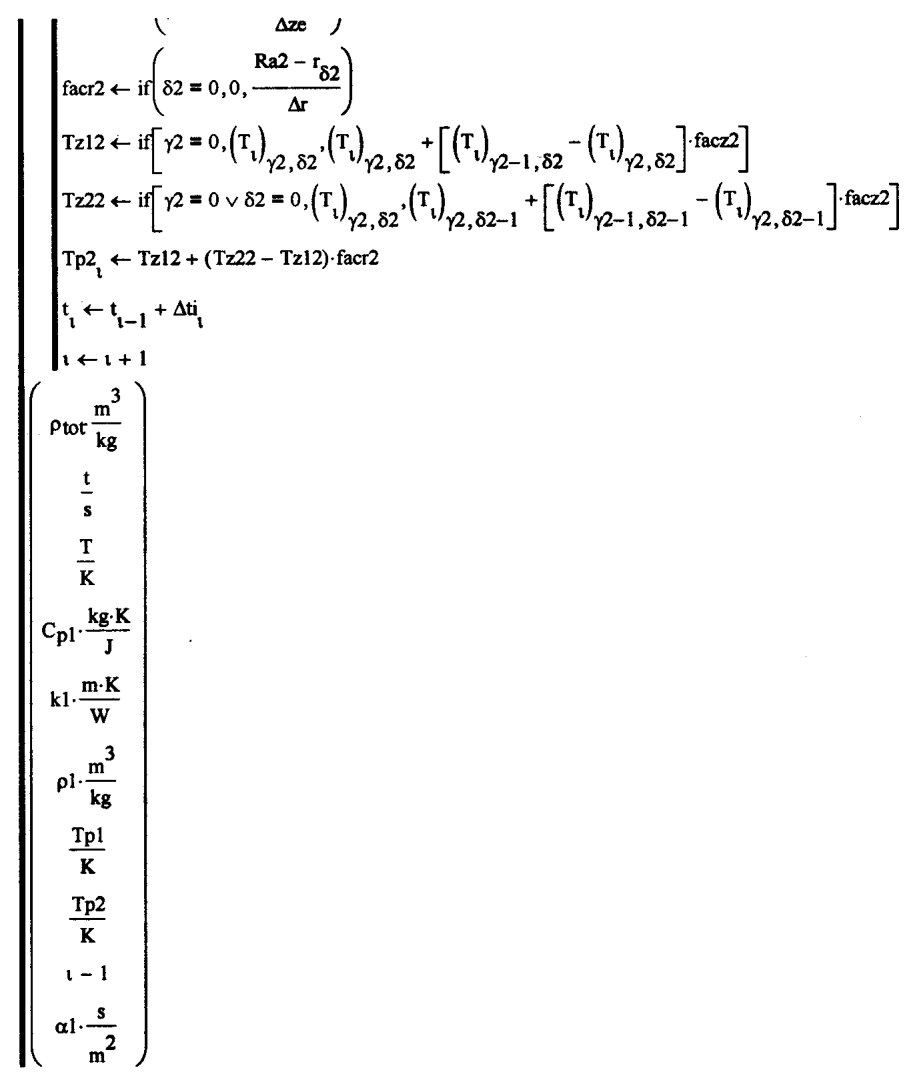

๑

With an assumption of $2 \mathrm{D}$ axisymmetric analysis, the heat diffusion equation in cylindrical coordinates becomes:

$$
\frac{1}{\alpha} \cdot \frac{\partial}{\partial t} \mathrm{~T}=\frac{1}{\mathrm{r}} \frac{\partial}{\partial \mathrm{r}}\left(\mathrm{r} \cdot \frac{\partial}{\partial \mathrm{r}} \mathrm{T}\right)+\frac{\partial^{2}}{\partial \mathrm{z}^{2}} \mathrm{~T}+\frac{\mathrm{qdot}}{\mathrm{k}}
$$

Defining the integer $p$ as the sequential time step where $n$ is the number of time steps:

$\mathrm{p}=1 . . \mathrm{n}$
Making an approximation using finite

difference and utilizing the definition of $p$

$$
\frac{\partial}{\partial t} T=\frac{\left(T_{p+1}\right)_{i, j}-\left(T_{p}\right)_{i, j}}{\Delta t}
$$




$$
\frac{1}{\alpha} \cdot \frac{\left(T_{p+1}\right)_{i, j}-\left(T_{p}\right)_{i, j}}{\Delta t}=\frac{\left(T_{p}\right)_{i+1, j}+\left(T_{p}\right)_{i-1, j}-2 \cdot\left(T_{p}\right)_{i, j}}{\Delta z}+\frac{\left(T_{p}\right)_{i, j+1}+\left(T_{p}\right)_{i, j-1}-2 \cdot\left(T_{p}\right)_{i, j}}{\Delta r^{2}}+\frac{1}{r} \cdot \frac{\left(T_{p}\right)_{i, j-1}-\left(T_{p}\right)_{i, j+1}}{2 \Delta r}+\frac{q d o t}{k}
$$

Which upon rearrangement becomes:

$$
\left(T_{p+1}\right)_{i, j}=\alpha \cdot \Delta t \cdot\left[\frac{\left(T_{p}\right)_{i+1, j}+\left(T_{p}\right)_{i-1, j}-2 \cdot\left(T_{p}\right)_{i, j}}{\Delta z^{2}}+\frac{\left(T_{p}\right)_{i, j+1}+\left(T_{p}\right)_{i, j-1}-2 \cdot\left(T_{p}\right)_{i, j}}{\Delta r}+\frac{1}{r} \cdot \frac{\left(T_{p}\right)_{i, j-1}-\left(T_{p}\right)_{i, j+1}}{2 \cdot \Delta r}+\frac{q d a t}{k}\right]+\left(T_{p}\right)_{i, j}
$$

Where $T(p)=$ Temperature at time step $p$ and $t$ and st represent time and time step respectively. The subscripts $i$ and $j$ are used to designate the nodal position in the $\mathrm{z}$ and $\mathrm{r}$ directions within the cylindrical coordinate system.

Output:

\# Time Steps

Time Step Counter

$\mathrm{n}:=$ Return $_{8} \quad \mathrm{n}=9.652 \times 10^{3} \mathrm{p}:=0 . . \mathrm{n}$
Temperature Profile

$\mathrm{T}_{\mathrm{p}}:=\operatorname{Return}_{2} \cdot \mathrm{C}$
Density Profile

$\rho:=\operatorname{Return}_{5} \cdot \frac{\mathrm{kg}}{\mathrm{m}^{3}}$
Core Coordinate

$\mathrm{c}:=$ floor $\left(\frac{\mathrm{b}}{2}\right)$

Thermal Diffusivit

N

Height of CWF

Average Density

$\rho_{\text {ave }}:=\operatorname{Return} 0 \cdot \frac{\mathrm{kg}}{\mathrm{m}^{3}}$

Final Density

$\rho_{\mathrm{f}}:=\rho_{\text {ave }}$

Time

Height $:=\frac{M}{\pi \cdot \mathrm{R}^{2} \cdot \rho_{\text {ave }}}$

Final Height

$\mathrm{H}_{\mathrm{f}}:=\frac{\mathrm{M}}{\pi \cdot \mathrm{R}^{2} \cdot \rho_{\mathrm{f}}}$

Point 1 Temperature

Time $:=$ Return $_{1} \cdot \mathrm{s}$

$\mathrm{TC} 1:=\operatorname{Return}_{6} \cdot \mathrm{C}$
Core Temperature

$\mathrm{T}_{\text {core }_{\mathrm{p}}}:=\left(\mathrm{T}_{\mathrm{p}}\right)_{\mathrm{c}, \mathrm{a}}$

Core Density

$\rho_{c_{p}}:=\left(\rho_{p}\right)_{c, a}$

Point 2 Temperature

$\mathrm{TC2}:=\operatorname{Return}_{7} \cdot \mathrm{C}$
Surface Temperature

$\mathrm{T}_{\text {surface }}:=\left(\mathrm{T}_{\mathrm{P}_{\mathrm{p}}}\right)_{0,0}$

Surface Density

$\rho_{s_{\mathrm{p}}}:=\left(\rho_{\mathrm{p}}\right)_{0,0}$

Thermal Diffusivity at Core

$\alpha_{c_{p}}:=\left(\alpha_{p}\right)_{c, a}$
Heat Capacity

$\mathrm{C}_{\mathrm{p}}:=\operatorname{Return}_{3} \cdot \frac{\mathrm{J}}{\mathrm{kg} \cdot \mathrm{K}}$

$\mathrm{k}:=\operatorname{Return}_{4} \cdot \frac{\mathrm{W}}{\mathrm{m} \cdot \mathrm{K}}$

Final distance between axial nodes

$$
\Delta z_{\mathrm{f}}:=\frac{\mathrm{H}_{\mathrm{f}}}{2 \cdot \mathrm{b}}
$$

Thermal Conductivity at Core

$\mathrm{k}_{\mathrm{c}_{\mathrm{p}}}:=\left(\mathrm{k}_{\mathrm{p}}\right)_{\mathrm{c}, \mathrm{a}}$

Heat Capacity at Core 


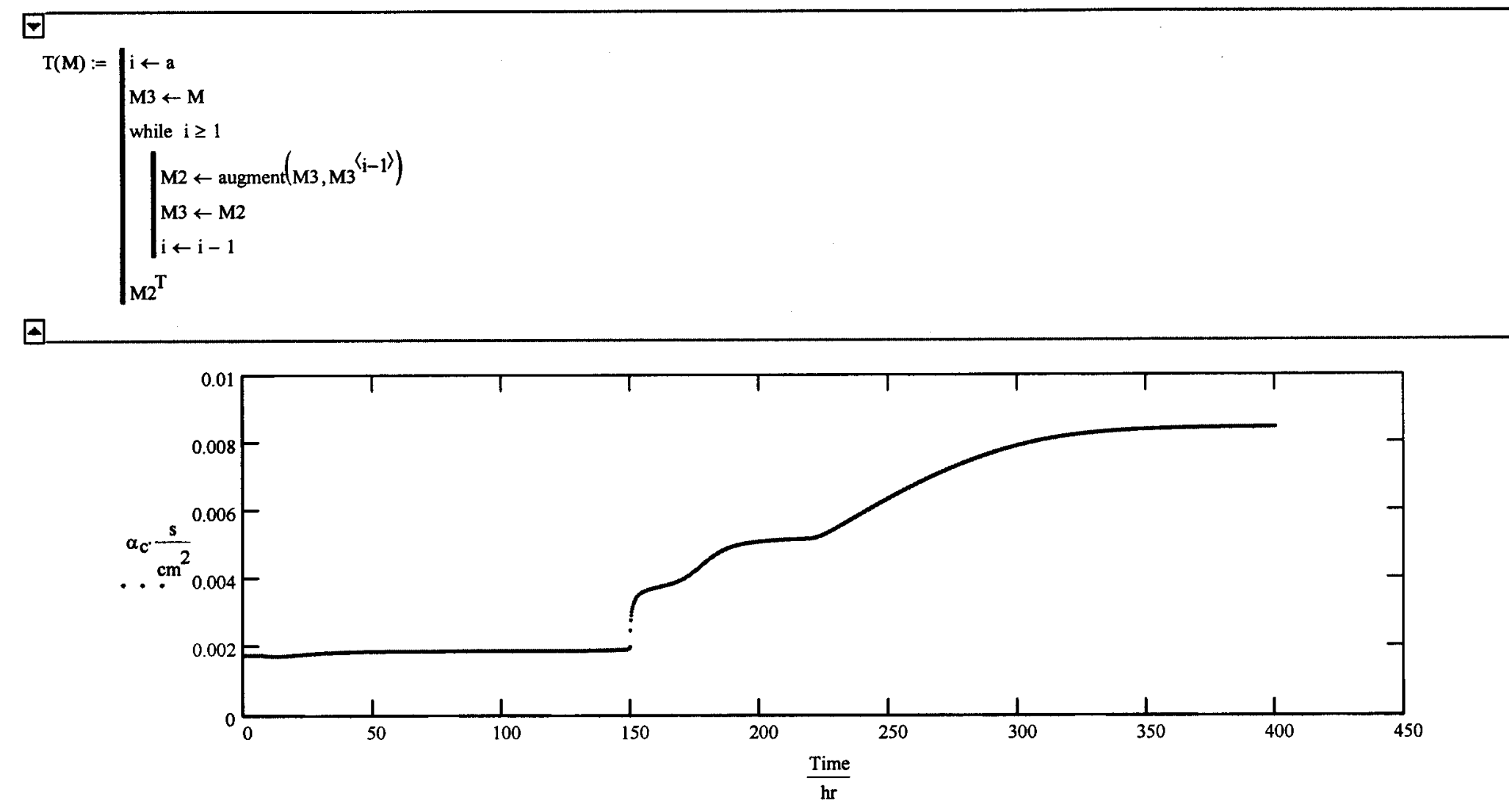


Plots:

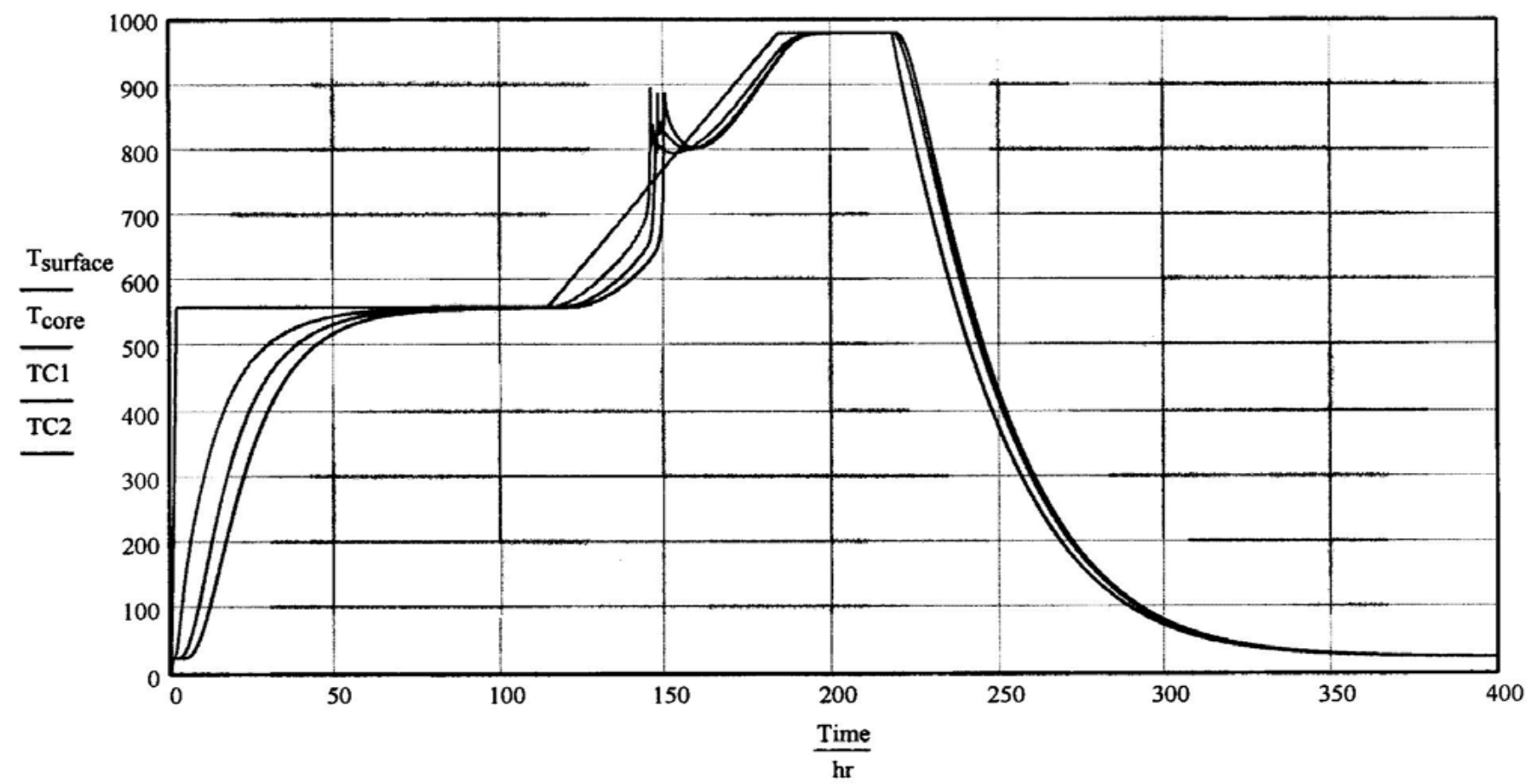




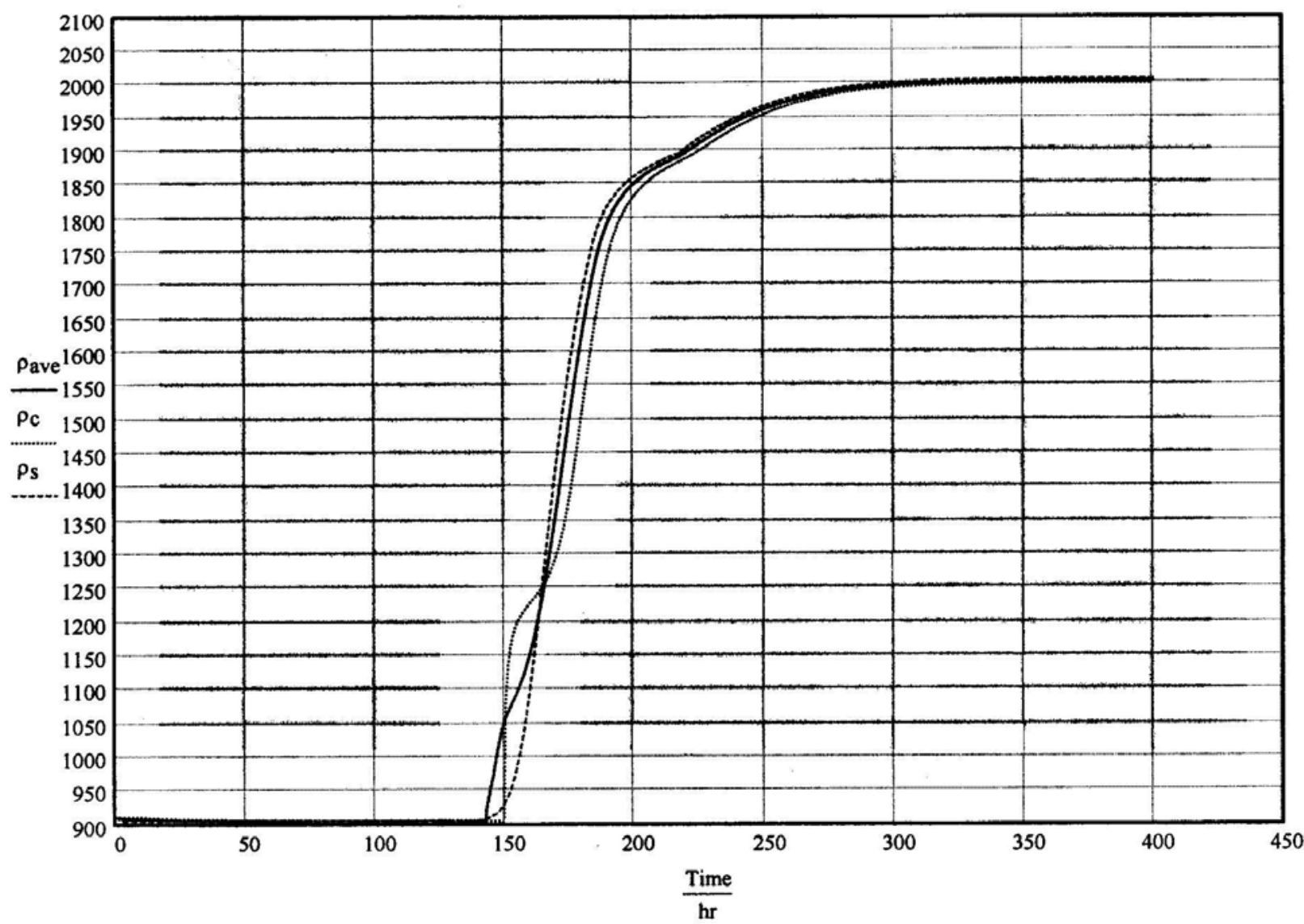

$\max \left(\rho_{\text {ave }}\right)=2.003 \times 10^{3} \frac{\mathrm{kg}}{\mathrm{m}^{3}}$

$\max \left(\mathrm{T}_{\text {core }}\right)=979.999 \mathrm{C}$ 
$\mathrm{H}=27.407$ in

$\mathbf{H}_{\mathbf{Z}}:=\mathbf{H}$

$H_{Z}=27.407$ in

$H_{b}:=76.938$ in

$Z:=\overrightarrow{\left(\text { Height }- \text { Height }_{0}+\mathrm{H}_{\mathrm{z}}\right)}$

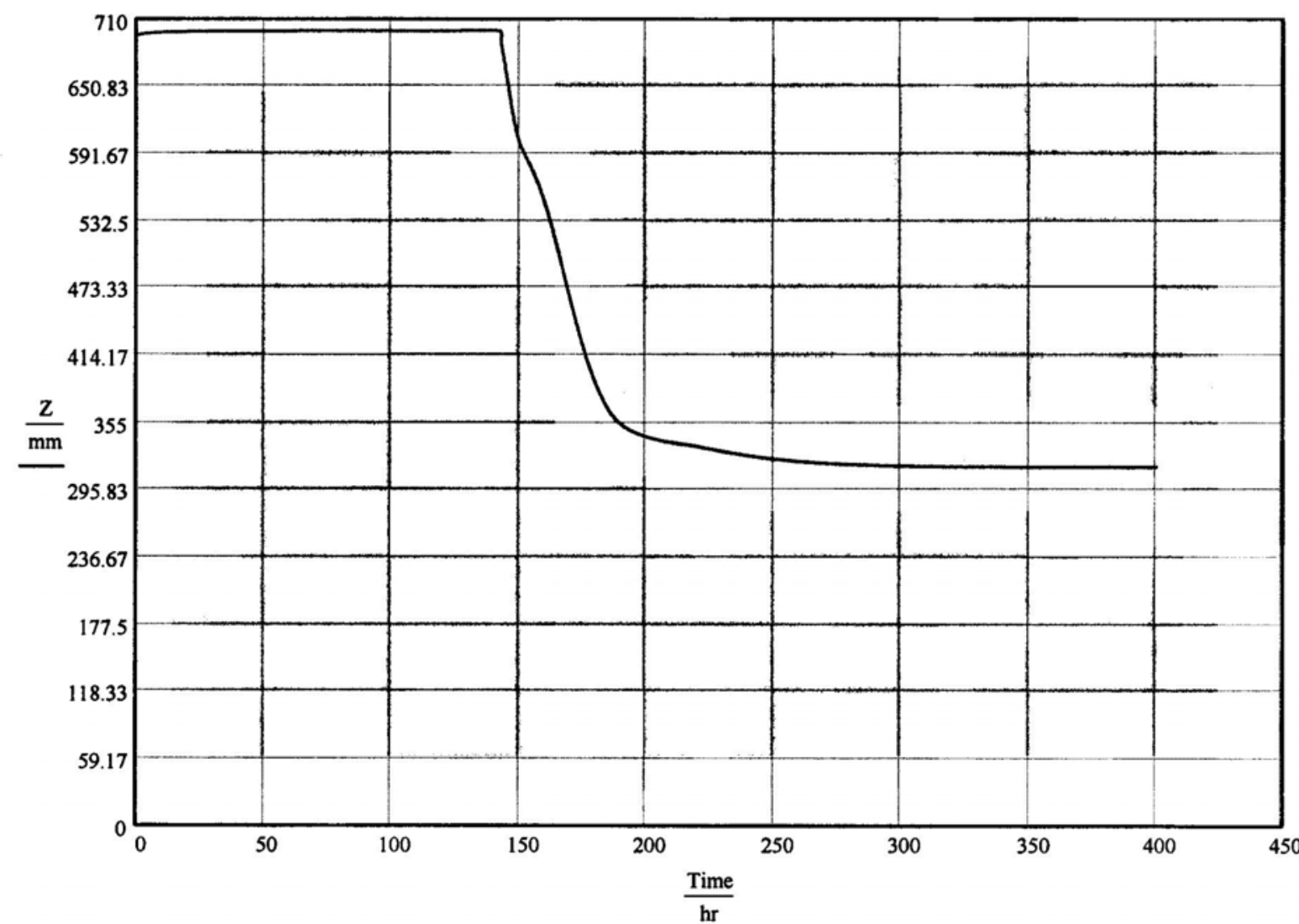

$\max (Z)=700.314 \mathrm{~mm}$

$\min (Z)=316.261 \mathrm{~mm}$ 


\begin{tabular}{|r|r|}
\hline & \multicolumn{1}{|c|}{0} \\
\hline 0 & 25 \\
\hline 1 & 158.269 \\
\hline 2 & 291.537 \\
\hline 3 & 424.806 \\
\hline 4 & 556.88 \\
\hline 5 & 560 \\
\hline 6 & 560 \\
\hline surface $=$ & 560 \\
\hline 7 & 560 \\
\hline 8 & 560 \\
\hline 9 & 560 \\
\hline 10 & 560 \\
\hline 11 & 560 \\
\hline 12 & 560 \\
\hline 13 & 560 \\
\hline 14 & 560 \\
\hline 15 & 560 \\
\hline
\end{tabular}
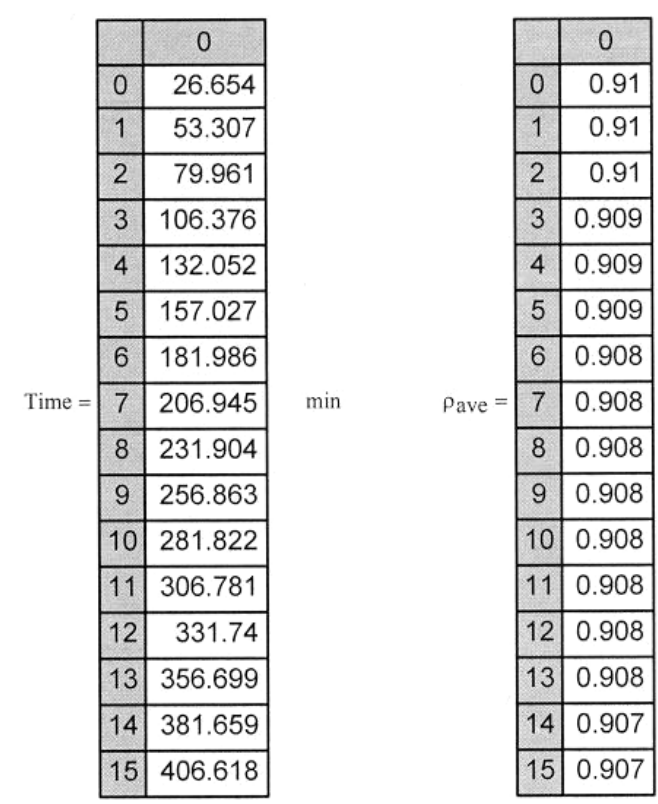

\begin{tabular}{|c|c|c|}
\hline & & 0 \\
\hline & 0 & 25 \\
\hline & 1 & 25 \\
\hline & 2 & 25 \\
\hline & 3 & 25 \\
\hline & 4 & 25 \\
\hline & 5 & 25 \\
\hline & 6 & 25 \\
\hline$\frac{\mathrm{gm}}{3} \quad \mathrm{~T}_{\text {core }}=$ & 7 & 25 \\
\hline & 8 & 25.014 \\
\hline & 9 & 25.085 \\
\hline & 10 & 25.28 \\
\hline & 11 & 25.699 \\
\hline & 12 & 26.448 \\
\hline & 13 & 27.626 \\
\hline & 14 & 29.311 \\
\hline & 15 & 31.555 \\
\hline
\end{tabular}

\begin{tabular}{|r|r|}
\hline & \multicolumn{1}{|c|}{0} \\
\hline 0 & 0 \\
\hline 1 & 25 \\
\hline 2 & 25 \\
\hline 3 & 29.704 \\
\hline 4 & 39.798 \\
\hline 5 & 54.75 \\
\hline 6 & 74.42 \\
\hline 7 & 94.702 \\
\hline 8 & 114.039 \\
\hline 9 & 131.969 \\
\hline 10 & 148.461 \\
\hline 11 & 163.666 \\
\hline 12 & 177.783 \\
\hline 13 & 191.007 \\
\hline 14 & 203.501 \\
\hline 15 & 215.395 \\
\hline
\end{tabular}




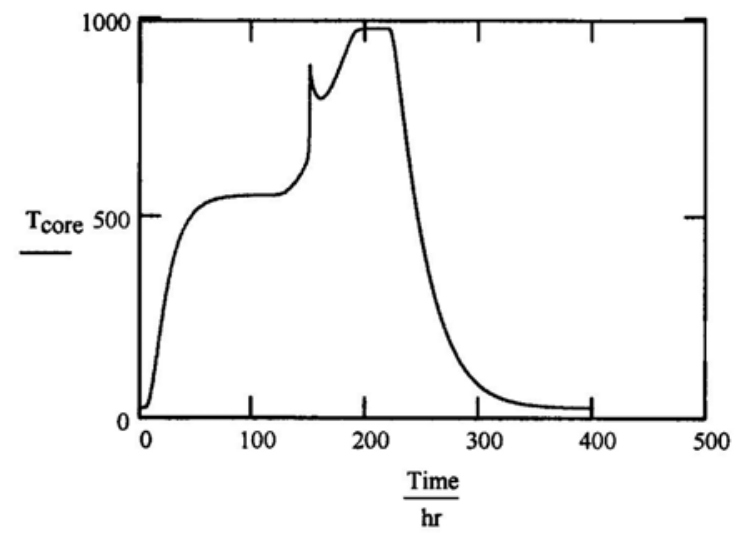

$\mathrm{n}=9.652 \times 10^{3}$

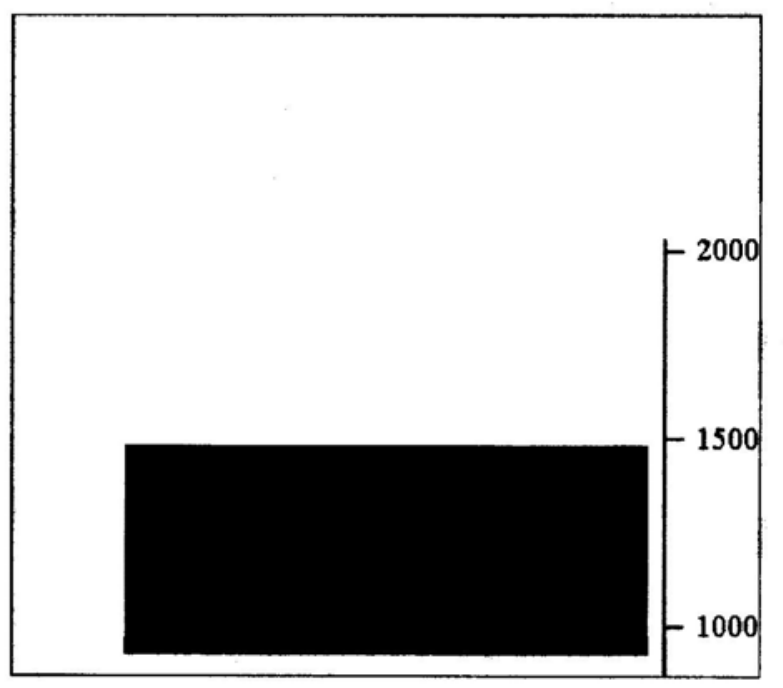

$\mathrm{T}\left(\mathrm{T}_{\text {PrRAME }}\right) \mathrm{T}\left(\mathrm{\rho}_{\mathrm{FRAME}}\right)$ 
$\mathrm{u}:=1 . . \mathrm{n}$

$\mathrm{t}_{\text {step }_{\mathrm{u}}}:=$ Time $_{\mathrm{u}}-$ Time $_{\mathrm{u}-1} \quad \mathrm{t}_{\text {step }_{0}}:=\mathrm{t}_{\text {step }_{1}}$

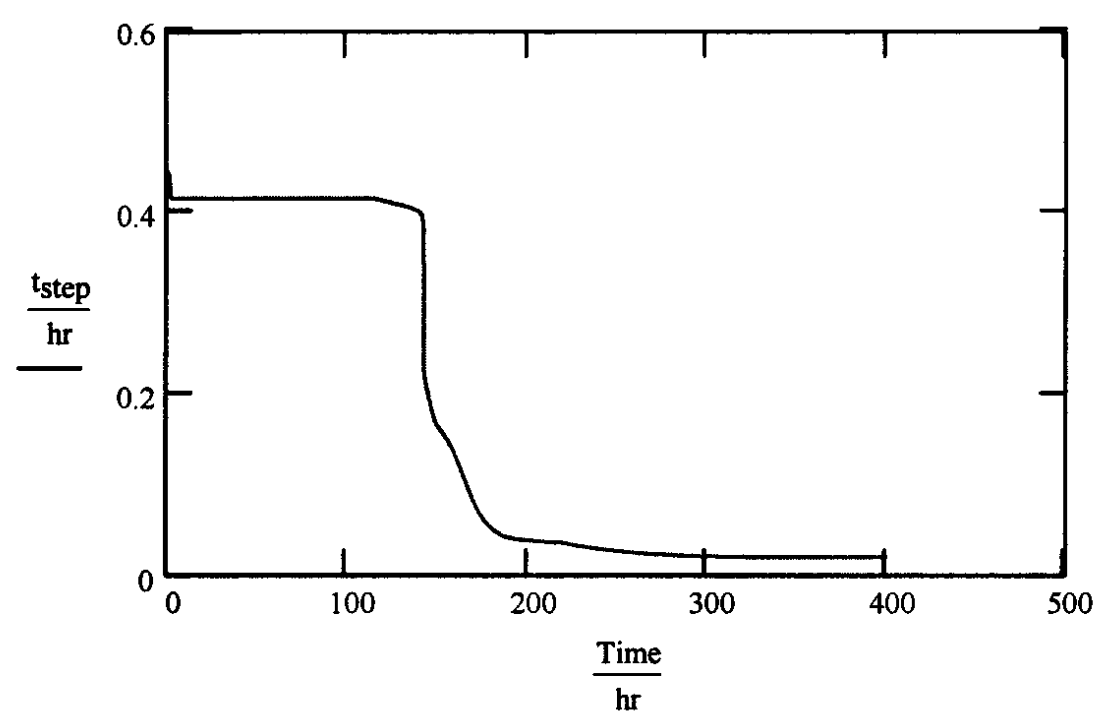

